Accounting for Spatial Correlation Errors in the Assimilation of GRACE into Hydrological Models through localization

M. Khaki, M. Schumacher, E. Forootan, M. Kuhn, J.L. Awange, A.I.J.M. van Dijk

PII:

DOI:

Reference:

To appear in:

Received date:

Revised date:

Accepted date:
S0309-1708(16)30816-8

10.1016/j.advwatres.2017.07.024

ADWR 2909

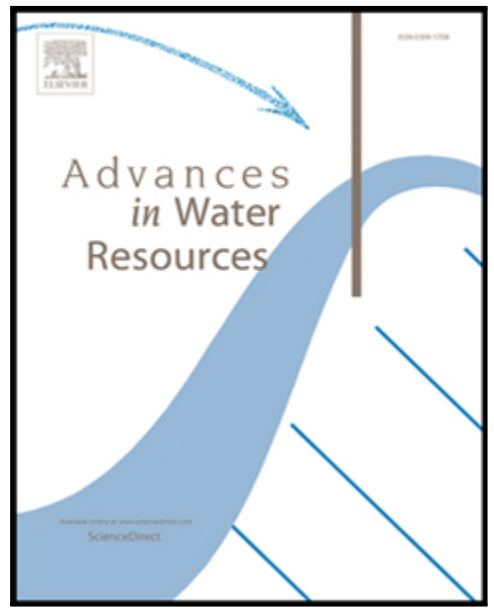

Please cite this article as: M. Khaki, M. Schumacher, E. Forootan, M. Kuhn, J.L. Awange, A.I.J.M. van Dijk, Accounting for Spatial Correlation Errors in the Assimilation of GRACE into Hydrological Models through localization, Advances in Water Resources (2017), doi: 10.1016/j.advwatres.2017.07.024

This is a PDF file of an unedited manuscript that has been accepted for publication. As a service to our customers we are providing this early version of the manuscript. The manuscript will undergo copyediting, typesetting, and review of the resulting proof before it is published in its final form. Please note that during the production process errors may be discovered which could affect the content, and all legal disclaimers that apply to the journal pertain. 


\title{
Accounting for Spatial Correlation Errors in the Assimilation of GRACE into Hydrological Models through localization
}

\author{
M. Khaki ${ }^{\mathrm{a}, 1}$, M. Schumacher ${ }^{\mathrm{b}}$, E. Forootan ${ }^{\mathrm{a}, \mathrm{c}}$, M. Kuhn ${ }^{\mathrm{a}}$, J. L. Awange ${ }^{\mathrm{a}}$, A. I. J. M. van Dijk ${ }^{\mathrm{d}}$ \\ ${ }^{a}$ Western Australian Centre for Geodesy and The Institute for Geoscience Research, Curtin University, Perth, \\ Australia. \\ ${ }^{b}$ School of Geographical Sciences, University of Bristol, Bristol, UK. \\ ${ }^{c}$ School of Earth and Ocean Sciences, Cardiff University, Cardiff, UK. \\ ${ }^{d}$ Fenner School of Environment and Society, the Australian National University, Canberra, Australia.
}

\begin{abstract}
\end{abstract}
Assimilation of terrestrial water storage (TWS) information from the Gravity Recovery And

Climate Experiment (GRACE) satellite mission can provide significant improvements in hydro-

logical modeling. However, the rather coarse spatial resolution of GRACE TWS and its spatially correlated errors pose considerable challenges for achieving realistic assimilation results. Consequently, successful data assimilation depends on rigorous modelling of the full error covariance matrix of the GRACE TWS estimates, as well as realistic error behavior for hydrological model simulations. In this study, we assess the application of local analysis (LA) to maximize the contribution of GRACE TWS in hydrological data assimilation. For this, we assimilate GRACE TWS into the World-Wide Water Resources Assessment system (W3RA) over the Australian continent while applying LA and accounting for existing spatial correlations using the full error covariance matrix. GRACE TWS data is applied with different spatial resolutions including $1^{\circ}$ to $5^{\circ}$ grids, as well às basin averages. The ensemble-based sequential filtering technique of the Square Root Analysis (SQRA) is applied to assimilate TWS data into W3RA. For each spatial scale, the performance of the data assimilation is assessed through comparison with independent in-situ ground water and soil moisture observations. Overall, the results demonstrate that LA is able to stabilize the inversion process (within the implementation of the SQRA filter) 17 leading to less errors for all spatial scales considered with an average RMSE improvement of $1854 \%$ (e.g., $52.23 \mathrm{~mm}$ down to $26.80 \mathrm{~mm}$ ) for all the cases with respect to groundwater in-situ measurements. Validating the assimilated results with groundwater observations indicates that LA leads to $13 \%$ better (in terms of RMSE) assimilation results compared to the cases with Gaussian errors assumptions. This highlights the great potential of LA and the use of the full

\footnotetext{
Email address: Mehdi.Khaki@postgrad.curtin.edu.au (M. Khaki )

${ }^{1}$ Contact details: Western Australian Centre for Geodesy and The Institute for Geoscience Research, Curtin University, Perth, Australia, Email: Mehdi.Khaki@postgrad.curtin.edu.au, Tel: 0061410620379
} 
22

error covariance matrix of GRACE TWS estimates for improved data assimilation results.

Keywords: Data assimilation, GRACE, Localization, Hydrological model.

\section{Introduction}

The Gravity Recovery And Climate Experiment (GRACE) satellite mission provides global time-variable gravity field solutions that have been used to obtain global terrestrial water storage (TWS) changes (Tapley et al., 2004). Several studies indicate that GRACE TWS can play an important role in better understanding surface and sub-surface physical processes related to water redistribution within the Earth system (e.g.) Huntington, 2006; Chen et al., 2007; Kusche et al., 2012; Forootan et al., 2014; van Dijk et al., 2014; Wouters et al., 2014). A growing number of studies has also been applying GRACE TWS to constrain the mass balance of hydrological models (e.g., Zaitchik et al., 2008; Thomas et al., 2014; van Dijk et al., 2014; Eicker et al., 2014; Tangdamrongsub et al., 2015; Reager et al., 2015; Khaki et al., 2017). This combination is motivated by the fact that hydrological models use conceptual or physical knowledge (or both) to simulate hydrological processes at global (e.g., Huntington, 2006; Coumou and Rahmstorf, 2012) and regional (e.g., Zaitchik et al., 2008; Chen et al., 2013; Munier et al., 2014) scales. The accuracy of simulations might be limited due to imperfect models (i.e., lack of knowledge about the processes or simplified model equations) and uncertainties in input and forcing data (Vrugt et al., 2013). Data limitation (both on temporal and spatial scales) also plays a substantial role in land hydrological modeling, especially for closing the water balance that requires reliable information about all storage compartments from which that of groundwater is very challenging. In this regard, GRACE TWS estimates are of great importance since they can be used through data assimilation to constrain the vertical summation of water storages (including groundwater) in the models.

Data assimilation is a technique to incorporate observations into a dynamic model in order to improve its state estimation (Bertino et al., 2003; Hoteit et al., 2012). It has been widely applied in the fields of ocean and climate science (Garner et al., 1999; Elbern and Schmidt, 2001; Bennett, 2002; Kalnay, 2003; Schunk et al., 2004; Lahoz, 2007; Zhang et al., 2012). In hydrological studies, different in-situ measurements (e.g., river discharge and soil moisture) have been assimilated into models (Liu et al., 2012) to improve their estimates of different 
51 hydrological quantities (see, e.g., Crow and Wood, 2003; Seo et al., 2003; Vrugt et al., 2005;

52 Weerts et al., 2006; Reichle et al., 2010).

The application of remotely sensed data in data assimilation for hydrological purposes has gathered interests in the past few years. This is especially due to the increased development and availability of satellite remote sensing systems such as Sentinel, Soil Moisture Active Passive (SMAP), GRACE, and satellite radar altimetry (e.g., Moradkhani et al., 2006; Clark et al., 2008; Houborg et al., 2012; van Dijk et al., 2014; Renzullo et al., 2014; Reager et al., 2015; Kumar et al., 2016). Data assimilation can improve various water compartments of hydrological models such as soil (e.g., Reichle et al., 2002, 2008; Brocca et al., 2010; Kumar et al., 2014; Renzullo et al., 2014), surface water (e.g., Alsdorf et al., 2007; Neal et al., 2009; Giustarini et al., 2011), and snow (e.g., Liu et al., 2013; Kumar et al., 2015) storages. A number of studies

has also investigated the possibility of using GRACE data to improve hydrological models (e.g., Zaitchik et al., 2008; Houborg et al., 2012; Li et al., 2012; Eicker et al., 2014; van Dijk et al., 2014; Tangdamrongsub et al., 2015; Kumar et al., 2016; Schumacher et al., 2016).

GRACE data with a suitable coverage, both temporally and spatially, provide a unique opportunity to study water storages in lands on gløbal and regional scales. The mission now provides 15 years of data with a global coverage, which provides the chance to study seasonal to decadal changes in TWS. Before using GRACE TWS in any assimilation framework, however, there are some important aspects which should be considered such as the temporal and spatial resolution mismatch between GRACE observations and model simulations, as well as existing spatial and temporal correlations in the time series of GRACE TWS and model simulations. Its spatial resolution is limited to a few hundred kilometers depending on the signal strength and the inversion technique applied to recover time-variable gravity fields (Schmidt et al., 2008). This coarse spatial resolution exists in both GRACE level 2 solutions provided in terms of spherical harmonics potential coefficients or mass concentration (mascon) solutions. Although mascon is provided on a finer spatial scale (e.g., $0.5^{\circ}$ ), the native resolution of the data is smaller (e.g., $3^{\circ}$; Watkins et al., 2015; Wiese, 2015). Different studies have tried to assimilate GRACE data in either basin scales (e.g., Zaitchik et al., 2008; Houborg et al., 2012; Li et al., 2012) or grid element scales (e.g., Eicker et al., 2014; Tangdamrongsub et al., 2015; Schumacher et al., 2016). GRACE level 2 products have been truncated (e.g., at degree and order 60-120). They also have been filtered (e.g., Swenson and Wahr, 2006; Kusche, 2007) 
82

resulting in low spatial resolutions. Upscaling of the original established TWS with a limited spatial resolution to create a high spatial resolution data (e.g., $1^{\circ}$ ) with grid points that are not independent of each other increases spatial correlation significantly (see e.g., Schumacher et al., 2016). Accounting for these correlations is important especially in the context of data assimilation, where complete knowledge of the data error structure including uncertainties and existing correlations is necessary.

Data assimilation as an inverse problem uses the covariance information of model simulations and observations. Significantly correlated errors yield covariance matrices that are bad conditioned or not invertible leading to inefficiency in filtering process during data assimilation. Due to the lack of information (or to enhance computations), the decision of uncorrelated data (Gaussian error for observations) is often made to deal with this problem, which can be realistic when observations are denser than models' grid, e.g., independent grid points of neighbours (Berger and Forsythe, 2004; Stewart et al., 2008). In contrast, when the spatial resolution of models is finer than the assimilated observations, it can lead to no improvement in the accuracy of final assimilation results (e.g., Liu and Rabier, 2003; Dándo et al., 2007; Stewart et al., 2008). In this regard, it is necessary to precisely consider the full GRACE error covariance for different spatial resolutions in data assimilation applications especially where the model spatial scale is finer than GRACE TWS, and the existing correlations in the observations are problematic (see e.g., Schumacher et al., 2016),

Most of the previous studies assimilated GRACE TWS (e.g., grid-based or basin averaged) into models while assuming white noise (i.e., uncorrelated observations). This, for basin averaged applications, might be justified to some extent as the spatial averaging of TWS observations adds up the non-Gaussian noise distributions and generates a mixture that is closer to Gaussian distribution according to the central limit theorem (Stone, 2004, Chapter 5). In this regard, for example, Zaitchik et al. (2008) applied GRACE TWS on a sub-basin scale (sub-basins of the Mississippi River) and assumed a Gaussian error (with zero correlation) for GRACE TWS measurements. Reichle et al. (2013) investigated the effects of coarse-scale satellite observations (e.g., GRACE) and vertically integrated measurements (such as TWS) on model variables within the assimilation system. For a grid-based assimilation of GRACE-TWS in models, Eicker et al. (2014) studied the relationship of different GRACE spatial resolutions on the data assimilation process and reported that there is always a trade-off between em- 
ploying GRACE data in a higher spatial resolution while keeping the GRACE error covariance matrices reasonably well conditioned. Girotto et al. $(2016,2017)$ have considered the fact that $1^{\circ}$ GRACE error covariances are spatially highly correlated and to address this issue, they have used a spatial correlation length of $3^{\circ}$ for the observation errors (see also Kumar et al., 2016; Khaki et al., 2017). Schumacher et al. (2016) indicated that both the characteristics of GRACE error correlation and spatial discretization of TWS observations are important on the performance of the data assimilation process. In another effort, van Dijk et al. (2014) proposed an alternative approach for estimating GRACE TWS errors in data assimilation. The triple collocation technique was used to merge model-derived storage in (sub-) surface compartments with TWS estimates from GRACE measurements (van Dijk et al., 2014). In the studies discussed above, GRACE error covariance for different spatial resolutions is hardly treated. For example, Eicker et al. (2014) considered error covariance of various spatial resolutions that were rescaled (e.g., rescaling $0.5^{\circ}$ to $5^{\circ}$ ) rather than solving for distinct spatial resolution individually (e.g., $0.5^{\circ}, 1^{\circ}$, and $\left.5^{\circ}\right)$.

In the present study, we extend the works above by employing a Local Analysis (LA) technique. LA allows utilization of different GRACE TWS spatial resolutions by addressing instability in data assimilation that arises from the GRACE covariance matrices of the corresponding spatial resolutions. The contribution of this study is, therefore, twofold: (i) we mathematically assess the efficiency of the localization technique to use GRACE TWS with its full error information and with high spatial resolution in an assimilation framework; and (ii), we compare the performance of a localization technique to in-situ data in a real case study covering the entire Australian continent. These will assess the ability of local data assimilation in maximizing the contribution of GRACE TWS into a hydrological model by considering its full error covariance matrix. Here, we use the full variance-covariance of GRACE to establish the observation error covariance matrices for the grid resolutions of $1^{\circ}, 2^{\circ}, 3^{\circ}, 4^{\circ}, 5^{\circ}$, and a basin scale, and examine their effects on data assimilation. More importantly, for the first time, we offer a solution to increase the performance of data assimilation in using GRACE data. A localization technique is applied to account for correlations in high spatial resolution observations, which can lead to a rank deficiency problem and correspondingly an instability in the data assimilation procedure. In terms of localization technique, Local Analysis (LA) of the filter (Evensen, 2003; Ott et al., 2004) is considered mainly due to its ability in dealing with correlations by spatially limiting the use of ensemble-based covariance information of high-dimensional systems to the limited 
local region (Ott et al., 2004). LA effects on each data assimilation scenario (i.e., using different spatial resolutions) are assessed to explore its ability for improving the results. In addition, the application of LA has the potential to minimize a large part of error sources in the ensemble filtering methods when a small number of ensembles is used (Mitchell and Houtekamer, 2000; Houtekamer and Mitchell, 2001).

GRACE TWS data is assimilated into the World-Wide Water Resources Assessment (W3RA, van Dijk, 2010) over Australia. The ensemble-based sequential technique of the Square Root Analysis (SQRA) filtering scheme represented by Evensen (2004) is used to assimilate GRACE TWS into W3RA. SQRA, which is a deterministic form of ensemble Kalman filtering, has considerable advantages in comparison to some existing methods in terms of the computational speed, simplicity, and its independency to an observation perturbation unlike traditional Kalman filtering methods (see detail in Section 3.1 and Khaki et al, 2017). In addition to implementing the LA, in order to further address possible problems that arise from ensemble size, sampling errors, and insufficient ensemble variance in ensemble-based techniques (Anderson et al., 2007; Oke et al., 2007), ensemble inflation is applied/This technique, which has frequently been used in previous works (e.g., Anderson and Anderson, 1999; Anderson et al., 2007; Ott et al., 2004), tries to increase the variance of ensembles around the ensemble mean by inflating prior ensembles (Anderson et al., 2007).

The remainder of this contribution is organized as follows: in Section 2, the GRACE TWS data, W3RA, and in-situ observations are introduced. The SQRA filtering scheme used for data assimilation, ensemble inflation, and the applied localization method are described in Subsection 3.1 and details of an experiment set up are provided in Subsection 3.2. In Section 4, the results of data assimilation and their evaluation against the in-situ validation data are presented and discussed, and finally in Section 5, the study is concluded.

\section{Datasets}

\section{1. $G R A C E$}

Monthly GRACE level 2 (L2) potential coefficients products along with their full error covariance information are obtained from the ITSG-Grace2014 gravity field model (MayerGürr et al., 2014). The solution is computed up to degree and order (d/o) 90 resulting in 
approximately $\sim 300 \mathrm{~km}$ spatial resolution at the equator. The study period (February 2003 to December 2012) is limited by the availability of the climate data (see Section 2.2) to force the hydrological model.

Following Swenson et al. (2008), degree 1 coefficients (http://grace.jpl.nasa.gov/data/getdata/geocenter/) are replaced to account for the movement of the Earth's centre of mass. Degree 2 and order $0\left(C_{20}\right)$ coefficients (http://grace.jpl.nasa.gov/data/get-data/oblateness/) are not well determined and are replaced by those from Cheng and Tapley (2004). Correlated noise in the TWS data products is reduced by applying de-striping and smoothing using a Gaussian averaging kernel with $300 \mathrm{~km}$ half radius following Swenson and Wahr (2006). This causes some degree of signal attenuation (Klees et al., 2008) and moving anomalies from one region to another (Chen et al., 2007). This leakage effect can lead to some degree of signal inference especially at the land-ocean boundary. In order to address this issue, following Swenson and Wahr (2002), we apply an isotropic kernel using a Lagrange multiplier filter to best balance signal and leakage errors over the entire Australia. This filter uses a basin averaging kernel method expanded in spherical harmonic coefficients and subsequently combined with L2 potential coefficients to improve the GRACE estimates (see details in Swenson and Wahr, 2002).

The filtered gravity fields, are then converted to TWS changes (following Wahr and Molenaar, 1998) over the entire Australia in both grid and basin scales. The amount of rainfall over Australia, especially over its northeast, western, and central parts, is low in comparison to other inhabited continents on Earth leading to prolonged drought in the interior regions (Forootan et al., 2016). This effect can be seen from the average precipitation (between February 2003 and December 2012) in Figure 1. This map shows small amount of rainfall over most parts of Australia (e.g., the western and eastern parts). Therefore, an accurate estimation of water storages (e.g., using hydrological models) is necessary to manage water resources in this region. TWS changes from GRACE are gridded into the spatial grid resolutions of $1^{\circ}, 2^{\circ}, 3^{\circ}, 4^{\circ}, 5^{\circ}$, and also a basin scale for 12 major Australian drainage divisions and river basin (cf. Figure 1). As a number of studies have used basin averaged GRACE TWS for data assimilation (e.g., Zaitchik et al., 2008; Houborg et al., 2012), we test the LA in both grid and basin scales. Accordingly, for each grid size as well as basin scale error covariance matrices are calculated using the full error information of the L2 potential coefficients for each month. Note that the errors in lower degree potential coefficients provided along with degree 1 coefficients and $C_{20}$ are sub- 
stituted into the GRACE covariance matrix. No correlation is considered between the GRACE covariance matrix and errors in the lower degree potential coefficients. This error information is then used to reach observation errors for data assimilation. To this end, following Schumacher et al. (2016), an error propagation is implemented to convert the full error information of the GRACE coefficients to TWS errors.

FIGURE 1

\subsection{W3RA}

In this study, we use the World-Wide Water Resources Assessment system (W3RA), which was developed in 2008 by the Commonwealth Scientific and Industrial Research Organisation (CSIRO) to monitor, represent and forecast/Australia's terrestrial water cycles (http://www.wenfo.org/wald/data-software/). W3RA is a grid distributed biophysical model that simulates water stores and flows with significant information of water storages over Australia (van Dijk, 2010; Renzullo et al., 2014). Globally distributed $1^{\circ} \times 1^{\circ}$ minimum and maximum temperature, downwelling short-wave radiation, and precipitation from Princeton University (http://hydrology.princeton.edu) are used as meteorological forcing data (see detail in Sheffield et al., 2006). The model parameters include effective soil parameters, water holding capacity and soil evaporation, relating greenness and groundwater recession, and saturated area to catchment characteristics (van Dijk et al., 2013). Model state in this study includes the W3RA water storages in the top, shallow, and deep root soil layers, groundwater storage, and surface water storage in a one-dimensional system (vertical variability). Here, we use W3RA (with a daily scale) for the same temporal coverage of GRACE (e.g., February 2003 to December 2012) and the spatial resolution of $1^{\circ} \times 1^{\circ}$. More detailed information on W3RA can be found in van Dijk et al. (2013).

\subsection{Validation Data}

We use groundwater in-situ measurements over the Murray-Darling basin extracted from the New South Wales Government (NSW) groundwater archive (http://waterinfo.nsw.gov.au/pinneena/gw.shtml) to evaluate the performance of applied data assimilation. Although data assimilation is done over entire Australia, due to limited 
availability of in-situ stations, the existing in-situ measurements over the Murray-Darling basin are used for result assessment. Measurements with data gaps and those that did not exhibit seasonal variations are flagged as belonging to confined aquifers and are excluded (Houborg et al., 2012; Tangdamrongsub et al., 2015). Therefore, daily and monthly well measurements of 54 spatially distributed stations over the basin (cf. Figure 1) are used and time series of groundwater storage anomalies are generated for each station. Selected well-water levels need to be converted to variations in groundwater (GW) storage in terms of equivalent water heights. This is usually done through the specification of yield estimates (e.g., Rodell et al., 2007; Zaitchik et al., 2008). However, such information does not exist in this study. Hence, following Tangdamrongsub et al. (2015), TWS variations from GRACE and soil moisture products from Global Land Data Assimilation System (GLDAS) NOAH (Rodell et al., 2004) are used to calculate the specific yield and scale the observed head water by modifying the magnitude of GW time series (Tregoning et al., 2012). As Tregoning et al. (2012) showed, the GW component can be extracted over Australia by removing the soil moisture component from GRACE TWS data. Other water compartments including biomass and surface water variations can be excluded due to their small contribution to regional scale mass variations within Australia. Through this approach, rather than assuming a constant specific yield everywhere (e.g., 0.1 by Tregoning et al., 2012), different yield values can be derived leading to a more realistic representation of groundwater systems in different areas.The calculated specific yields range between 0.08 and 0.16 , falling within the $0.05-0.2$ range suggested by the Australian Bureau of Meteorology (BOM) and Seoane et al. (2013), hence justifying the application of the method. The extracted yield factor is used at each in-situ location to scale the observed in-situ head time series (see also Rodell et al., 2007; Longuevergne et al., 2013). After removing temporal averages of in-situ groundwater time series, the anomaly time series are used in this study to assess W3RA estimates after the assimilation process.

Further result assessment is done using in-situ soil moisture measurements. These datasets are obtained from the moisture-monitoring network (http://www.oznet.org.au/) known as OzNet network and spotted in the Murrumbidgee catchment (Smith et al., 2012). OzNet network provides long-term records of measured volumetric soil moisture at various soil depths at 57 locations across the Murrumbidgee catchment area (cf. Figure 1). The anomalies of in-situ soil moisture measurements are calculated and then averaged into daily scale. Following Renzullo et al. (2014), 0-8 cm data is used to evaluate the estimated model top-layer soil mois- 
ture and the 0-30 $\mathrm{cm}$ and 0-90 $\mathrm{cm}$ measurements are applied for the evaluation of the model shallow root-zone soil moisture estimation.

\section{Data Assimilation}

\subsection{Methods}

\subsubsection{Square Root Analysis (SQRA)}

The solution of the data assimilation problem is based on Bayes' theorem (Jazwinski, 1970; van Leeuwen et al., 1996), which tries to improve the model state by updating the prior Probability Density Function (PDF) whenever new observations are introduced. The sequential data assimilation technique solves the Bayesian estimation problem numerically by providing a probabilistic framework and sequentially estimates the whole system using propagated information (ensembles) only forward in time (Jardak et al., 2007). There are various filtering methods in this framework, however, one of the mostly applied techniques is ensemble-based Kalman filter. In this study, we use the square root analysis (SQRA) scheme for the Ensemble Kalman Filter (EnKF), represented by Evensen (2004) as a data assimilation filtering method. SQRA is a deterministic form of ensemble-based Kalman filters and uses a statistical sample of state estimates (Sakov et al., 2008). The model state contains $\mathrm{N}$ different vectors ( $N$ is the number of ensembles), each with the same size of the model state variables. The forecast model state is represented by $X^{f}=\left[X_{1}{ }^{f} \ldots X_{\mathcal{N}}{ }^{f}\right]$, where $X_{i}{ }^{f}(i=1 \ldots N)$ is the $i$ th ensemble (hereafter 'f' stands for forecast and 'a' stands for analysis). The model state forecast error covariance of $P^{f}$ is defined by:

$$
P^{f}=\frac{1}{N-1} \sum_{i=1}^{N}\left(X_{i}^{f}-\bar{X}^{f}\right)\left(X_{i}^{f}-\bar{X}^{f}\right)^{T}=\frac{1}{N-1} A^{f} A^{f^{T}},
$$

where $\bar{X}^{f}$ is the ensemble mean and can be calculated using,

$$
\bar{X}^{f}=\frac{1}{N} \sum_{i=1}^{N}\left(X_{i}\right)
$$

Forecast ensemble of anomalies, $A^{f}=\left[A_{1}{ }^{f} \ldots A_{N}{ }^{f}\right]$, is the deviation of model state ensembles from the ensemble mean,

$$
A_{i}^{f}=X_{i}^{f}-\bar{X}^{f}
$$


SQRA eliminates the need for the perturbation of measurements, which is essential in traditional EnKF (Burgers et al., 1998). Instead, SQRA uses unperturbed observations without imposing any additional approximations like uncorrelated measurement errors (Evensen, 2004) by introducing a new sampling scheme. Rather than updating each sample separately in the analysis step, SQRA updates all of them in two stages; firstly by updating the ensemble-mean using $\bar{X}^{f}$ (cf. Equation 1) as,

$$
\begin{gathered}
\bar{X}^{a}=\bar{X}^{f}+K\left(y-H \bar{X}^{f}\right), \quad i=1 \ldots N, \\
K=P^{f}(H)^{T}\left(H P^{f}(H)^{T}+R\right)^{-1}
\end{gathered}
$$

where $\bar{X}^{a}$ is the mean analysis state, $K$ represent the Kalman gain, $y$ and $R$ are the observation vector and associated covariance matrix. The transition matrix from the state vector space to the observation space is shown by $H$. Next, SQRA computes the ensemble anomalies. In this regard, one needs to first calculate the ensemble version of the analysis error covariance matrix, which can be done using Equation 6. Afterward, by inserting the forecast ( $P^{f}$ from Equation 1) and analysis $\left(P^{a}\right.$ from Equation 6$)$ error covariances in Equation 7 and solving for $A^{a}$, analysis ensemble of anomaly can be computed.

$$
\begin{gathered}
P^{a}=\frac{A^{a}\left(A^{a}\right)^{T}}{N-1} \\
P^{a}=(I-K H) P^{f}
\end{gathered}
$$

After a few simplification steps (cf. Evensen, 2004), $A^{a}$ can be obtained by,

$$
A^{a}=A^{f} V \sqrt{I-\Sigma^{T} \Sigma \Theta^{T}},
$$

where $\Sigma$ and $V$ are calculated using singular value decomposition of $A^{f}\left(A^{f}=U \Sigma V^{T}\right) . \Gamma$ refers to the singular value decomposition and $\Theta$ is a random orthogonal matrix (e.g., the right singular vectors from a singular value decomposition of a random $N \times N$ matrix) for ensemble redistribution of the variance reduction (cf. Evensen, 2004, 2007; Khaki et al., 2017).

\subsubsection{Filter Tuning}

Many studies have previously investigated the sensitivity of ensemble-based schemes on ensemble size (e.g., Houtekamer, 1995; Houtekamer and Mitchell, 1998; Keppenne, 2000; Mitchell et al., 2002; Keppenne and Rienecker, 2002). It has been proven that a large number of ensemble members in ensemble data assimilation systems causes computation time to 
significantly increase while using a small ensemble size can also be problematic, as it can lead to filter divergent or inaccurate estimation (Tippett et al., 2003). A successful ensemble-based filter needs to adequately span the model sub-space for a better approximation of probability distribution of the background errors (Ott et al., 2004). This, however, can be very challenging once a small ensemble number (considerably less than the model dimension) is used. To tackle this problem, we apply ensemble inflation, which uses a small coefficient to separately inflate prior ensemble deviation from the ensemble-mean and increases their variations (Anderson et al., 2007). Here, we use a constant factor ( $S=1.12$; Anderson, 2001) to inflate the ensemble perturbations as,

$$
X^{\prime f}=S\left(X^{f}-\bar{X}^{f}\right)+\bar{X}^{f},
$$

with $X^{\prime f}$ representing the new forecast state, which contains the inflated ensemble perturbation.

A further solution when dealing with a limited ensémble number is the application of localization techniques initially proposed by Houtekamer and Mitchell (2001). In this study, we use the Local Analysis (LA) scheme not only to address the issue of the small ensemble number, but also to investigate its effects in dealing with the GRACE error covariance for different spatial resolutions. LA works by restricting the information used for the covariance matrix computation to a spatially limited area and/uses only measurements located within a certain distance from a grid point (Evensen, 2003; Ott et al., 2004; Khaki et al., 2017).

In using LA, at each horizontal grid point $(m, n)$, with $m$ and $n$ representing geographic latitude and longitude directions, respectively, the selected measurements close to the grid point contribute to the SQRA filtering process. This means that only particular state variables close to the point $(m, n)$ within an assumed distance and corresponding observations at the same locations are used in the assimilation process. To do this, a local system state vector, observations, and their covariance matrix need to be chosen at each grid point separately. Following Ott et al. (2004), a model state vector $X(r)$ ( $r$ is a two-dimensional vector with $\left.r_{m n}\right)$ is used to achieve the local forecast state vector $X^{f}{ }_{m n}$ in Equation 9 using a linear operator $M_{m n}$ by,

$$
X^{\prime f}{ }_{m n}=M_{m n} X^{\prime f}(r)
$$

At the specific grid point of $\left(m_{0}, n_{0}\right), X^{\prime f}{ }_{m n}$ contains the information of $X^{\prime f}\left(r_{m+m_{0}, n+n_{0}}\right)$ with $-l \leq m-m_{0}, n-n_{0} \leq l$ ( $($ localization length $)$ and limited to grid points close to $\left(m_{0}, n_{0}\right)$ 
within a $(2 l+1)$ by $(2 l+1)$ patch (Ott et al., 2004).

Local state vectors and observations within the local region $\left(y_{m n}\right)$ with covariance matrix $R_{m n}$ can then be used in SQRA to locally estimate the model state for each grid point. In case of using a gridded GRACE TWS dataset in a finer spatial resolution (e.g., $1^{\circ}$ and $2^{\circ}$ ), the calculated error covariances have rank deficiency mainly due to correlation errors (see more details in Section 4.1). This problem can cause instability in the data assimilation procedure. Applying LA, therefore, can be helpful since it numerically resolves the possible singularity in the filtering process during data assimilation. Ott et al. (2004) proved that LA yields a good approximate representation of the background covariance matrix using a small ensemble number with a rank much lower than the state dimension. LA localization can also be used in the vertical direction, where different water compartments (e.g., shallow and deep soil moisture, groundwater storage, and surface water storage) exist. This can be helpful to vertically decrease the influence of the layers on each other by limiting the filtering process to specific layers, especially when there is a high correlation between the observed components at different layers. Here, however, LA is applied only horizontally because the GRACE TWS observation at each grid point is assimilated to an aggregate of water compartments at the same point. Therefore, a vertical variability in system states is not reflected in the observation error covariance. Furthermore, we are more interested in monitoring the performance of the localization scheme on the GRACE covariance matrix rather than a state covariance matrix. Different trial localisation lengths $\left(2^{\circ}\right.$ to $10^{\circ}$ for gridded TWSs) are applied in this study and their results are assessed against independent groundwater in-situ measurements (cf. Section 2.3) to find the best case (see details in Section 4.2).

\subsection{Assimilating GRACE Data}

In order to address the rather low temporal resolution of GRACE (approximately 30 days), its monthly data and errors are interpolated to 5-day data following Tangdamrongsub et al. (2015), the spline interpolation between consecutive months is used to generate these time series, which allows the ensemble to gradually change between updates. Next, the mean water storage over the study area between 2003 and 2013 is calculated from the W3RA and is added to GRACE TWS changes time series in order to achieve the absolute values. The provided observations are assimilated into W3RA for the 5 different grid resolutions of $1^{\circ}, 2^{\circ}, 3^{\circ}, 4^{\circ}$, and $5^{\circ}$ and also in basin scales. 
The $1^{\circ} \times 1^{\circ}$ spatial resolution of the model leads to a model state vector $\left(X^{f}\right)$ with 794 elements within the Australian continent. Each of these elements contains different water compartments. This means that the state vectors for every grid point in our experiments are composed of the different water storages, including top soil, shallow soil, and deep soil water, canopy, snow, surface, and groundwater. The observations matrix $(H)$ accumulates the state variables (the individual water storages) at each grid point to determine the simulated TWS in order to update them with the GRACE TWS during assimilation. In the update steps, the 5-day temporal average update increment (i.e., the difference between the simulated TWS and GRACE TWS) is applied.

Initial ensemble members are generated by perturbing the meteorological forcing fields following Renzullo et al. (2014). In this regard, the three most important forcing variables including precipitation, temperature, and radiation and their reported error characteristics (Sheffield et al., 2006) are used. To generate the perturbations, we assume a multiplicative error of $30 \%$ for precipitation, an additive error of $50 \mathrm{Wm}^{-2}$ for the shortwave radiation, and an additive error of $2^{\circ} \mathrm{C}$ for temperature (Jones et al., 2007; Renzullo et al., 2014). Monte Carlo sampling of multivariate normal distributions with the errors representing the standard deviations without considering correlations (spatial and/or temporal) are used to produce an ensemble (according to Renzullo et al., 2014). Different ensemble sizes (30-120) and their spread are tested. The selected number of 72 members agrees with the suggestion by Oke et al. (2008) and shows promising performance and is used in this study. The perturbed meteorological forcing datasets, then, are integrated forward with the model for two years (January 2001 to January 2003). This provided a set of state vectors at the beginning of the study period, considered as the initial ensemble. A schematic illustration of the assimilation process steps is provided in Figure 2.

\section{Figure 2.}

\section{FIGURE 2}

\section{Results}

In the following, we first analyze the effects of GRACE TWS spatial scaling on the error covariance matrix. Then, LA behavior in dealing with GRACE error covariance with different spatial resolutions is addressed. Afterwards, we evaluate the results of data assimilation 
using LA with respect to different resolutions against the in-situ groundwater and soil moisture products. These results are also compared with the data assimilation process without applying LA (with a consideration of zero correlation in GRACE data) to be able to better investigate its effects on the model estimations.

\subsection{Scaling Effect}

In this section, we review the behavior of assimilating GRACE TWS data for different spatial resolutions into the W3RA model. To this end, GRACE TWS is assimilated with the following spatial resolutions, $1^{\circ}, 2^{\circ}, 3^{\circ}, 4^{\circ}, 5^{\circ}$, and a basin scale to monitor the effects of localization on the process. For each of the spatial resolution considered, 5-day GRACE TWS data (cf. Section 3.2) are assimilated into the model to address the coarser GRACE temporal scale in comparison to the model. As an example, in Figure 3, we compare the assimilated time series using the $1^{\circ} \times 1^{\circ}$ observations for a monthly (Figure 3a) and 5-day temporal scale over an arbitrary point (Figure 3c) to show the effect of temporal rescaling. The denser temporal resolution in Figure 3c eventuates in a much smoother time series. This is more obvious in Figures $3 \mathrm{~b}$ and $3 \mathrm{~d}$, which show only one year of the time series, respectively presented in Figures 3a and 3c. Given daily time steps of W3RA, assimilating GRACE TWS data once a month (e.g., in the middle of the month) causes unnatural jumps at the assimilation steps (cf. Figure 3b). Such a jump is much smaller in magnitude in Figure 3d where a 5-day sampling interval is used. This leads to keeping the ensemble spread smoother without significant artifacts or temporal discontinuities. It should be mentioned that another solution for keeping ensemble spread smooth is the application of ensemble Kalman smoother (EnKS), which redistributes analysis increments evenly over all days of the month with the expense of more computational cost (see, e.g., Zaitchik et al., 2008; Houborg et al., 2012).

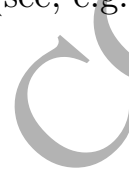

FIGURE 3

We can now assess the behaviour of LA on data assimilation when the full error covariance of GRACE is used for the different applied spatial scales. Figure 4 shows the estimated correlation matrices for each grid resolution (following Eicker et al., 2014). This figure helps in understanding how different grid resolutions affect the corresponding observation covariance matrix. It can be seen that the spatial scaling influences the correlation between points. The 
correlation (off-diagonal elements) between grid points decreases for larger grid resolutions, with the least for the $5^{\circ}$ gridded TWSs, which is significantly less than that of $1^{\circ}$ grid resolution. This correlation is even smaller when the basin scale GRACE data is considered. To clarify how this affects the data assimilation procedure, Table 1 indicates the number of gridded observations in various grid resolutions and the estimated ranks of covariance matrices. We find that there is a close relationship between the grid resolution and covariance matrix rank (cf. Table 1). As mentioned earlier, rank deficiency problem in covariance matrices causes instability in the data assimilation procedure and inaccurate estimations. The application of LA, however, numerically addresses this issue. It can be seen that LA affects the estimated covariance matrix rank for each grid resolution. Details on the number of observations and the rank of the respective covariance matrices (cf. Table 1) demonstrates the LA effect on improving the process by solving the mathematical problem related to the rank deficiency especially in the cases of $1^{\circ}$ and $2^{\circ}$.

\section{FIGURE 4}

\section{TABLE}

Rank deficiency likely happens for error/covariance matrices of GRACE TWS with grid resolutions that GRACE can resolve (e.g., $3^{\circ}$ or coarser). However, when using smaller grid resolutions, the matrix does not have a full rank leading to instabilities in the data assimilation procedure. Although applying GRACE data at lower spatial resolutions might be helpful in dealing with the covariance matrix, this will reduce the number of observations during data assimilation process (cf. Table 1) leading to some loss of signal in the observations. This might not be obvious considering the spatial correlation between grid points for higher resolution GRACE TWS. However, we show that using more observations and considering their full error covariance information in the assimilation process allows more information to be transferred with a higher number of observations into the system states. In this regard, we use the frequently empløyed indexes of Shannon Information Content (SIC or entropy reduction) and degrees of freedom (Dof) to measure information, which is transferred from observations into the system states (Rodgers, 2000) at the assimilation steps. SIC $\left(\frac{1}{2} \ln \left(P^{f} / P^{a}\right)\right)$ uses the information in the state probability density function (pdf) before and after assimilation to reflect a real-valued functional (Shannon and Weaver, 1949). Dof $\left(n-\operatorname{trace}\left(P^{a} / P^{f}\right)\right.$, with $n$ number of observations) 
on the other hand, is a measure of the amount of information from observations that is used (Stewart et al., 2008). For each grid resolution, the indexes of SIC and Dof are measured (Figure 5).

\section{FIGURE 5}

It can be seen in Figure 5 that by decreasing the spatial resolution, some information contained within the observations is lost. Therefore, although increasing the scale size (reducing the resolution) might be helpful in dealing with GRACE error covariance, it is at the cost of losing part of the signal. This justifies the application of LA, which allows us to use information with a higher spatial resolution in datasets.

As outlined in section 3.1.2, one important effect of LA is underestimating the influences of spatially distant grid points on each other. The distance in localization preserves the information in observations close to each other while at the same time making it possible to use full error covariance information. To demonstrate this, we consider the correlation coefficient of the arbitrary point (at a location $136.6854^{\circ} \mathrm{E}$ and $23.9015^{\circ} \mathrm{S}$ ) to the other grid points in Figure 6. This point is chosen to be approximately in the middle of the study area for a better visual representation while similar results are achieved for all other grid points. We integrate the model and performed data assimilation using the $1^{\circ}$ GRACE TWS (as the worst case among different applied resolutions) during the study period. The average correlation coefficients between the arbitrary point and the other grid points before and after assimilation using LA are then measured. Figure $6 \mathrm{~b}$ shows how LA successfully reduces the correlation coefficients for more distant grid elements but maintains the correlations in the close vicinity.

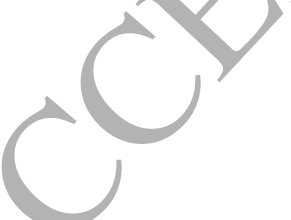

FIGURE 6

The important point to consider when using LA is the removal of some information from the data, which is not desirable. Thus, attention needs to be taken when choosing the localization length to preserve the adequate continuity of analysis on adjacent points (Zeng, 2014). LA length depends on the observation density and can be chosen arbitrarily. After testing different localization lengths, it is found that a small length (e.g., less than $5^{\circ}$ for $1^{\circ} \times 1^{\circ}$ GRACE TWS) can result in large errors even though there would be no inverse problem in assimilation filter. 
We use groundwater in-situ measurements to assess the results of applying different localization lengths $\left(2^{\circ}\right.$ to $10^{\circ}$ for gridded TWSs). For every scenario (different grid resolutions), we interpolate assimilation time series at the location of the groundwater in-situ and calculate the root-mean-square error (RMSE). The average computed RMSE of each grid resolution for the applied lengths (Figure 7) show that better results are obtained using the $5^{\circ}$ localization halfwidth length compared to the other applied localization lengths.

\section{FIGURE 7}

A similar experiment is implemented to find efficient localization length for a basin scale spatial resolution. For each basin, we test different lengths mostly larger than those for grid scales (e.g., $5^{\circ}$ to $15^{\circ}$ with the best performance of $10^{\circ}$ radii in average) and estimate TWS errors using the GRACE TWS data where in-situ measurements are not available for all basins. The localization length with the least error for each basin (Figure 8) is used to assess the LA effects at the basin scale and also to compare corresponding results with grid scale resolutions.

\section{FIGURE 8}

\subsection{Assessment with in-situ data}

Post processed in-situ measurements of groundwater changes (cf. Section 2.3) over the Murray-Darling basin as well as OzNet soil moisture network in the Murrumbidgee catchment (see Figure 1 for the location of the catchment) are used to evaluate the assimilation results. First, to compare the time series obtained from assimilation results with those of in-situ measurements, the GW results for each spatial resolution considered are spatially interpolated using the nearest neighbor (the closest four data values) to the location of the in-situ measurements. Afterward, the error time series are computed as the difference between the estimated GW and in-situ GW measurements. We then estimate average errors using these time series for each scenario of data assimilation.

The TWS time series of the assimilation process for the case of $3^{\circ}$ is shown in Figure 9a. Data assimilation with this spatial resolution results in a minimum GW error compared to the in-situ measurements. This figure also contains the open loop time series which refers to the estimations without implementation of any data assimilation and the assimilated observations. 
The absolute errors, i.e., the difference between the in-situ measurements and either the open loop or the assimilated estimates (for the best case of $3^{\circ}$ spatial resolution) are presented in Figure 9b. The assimilated time series fits well with the groundwater in-situ measurements (cf. Figure $9 \mathrm{a})$ and results in a higher correlation than the open loop time series (85\% average). Note that in terms of representing the hydrology, sometimes the estimates do not really depict the signal of the in-situ measurements. In some instances, the error (for no assimilation) is as large as the signal itself. This could be due to the fact that W3RA only simulates the dynamics of unconfined aquifers, that is, groundwater that receives soil drainage and discharges into streams. In some cases, a deeper (confined) aquifer underneath can also affect groundwater measurements. Nevertheless, data assimilation causes the updated time series to reflect better the real fluctuations in groundwater storage in most of the cases an given by the in-situ measurements.

\section{FIGURE}

The average estimated error of all GW in-situstations during the study period for each scenario illustrates the LA performances for the different spatial resolutions (Figure 10). The least error is obtained from the $3^{\circ}$ spatial resolution by comparing assimilation results of all scenarios. In addition, to be able to monitor the effectiveness of LA, data assimilation is also applied using GRACE-derived TWS and only diagonal elements of its error covariance matrix. Results without applying LA (represented in Figure 10) refers to this case where correlations between grid points are neglected. This comparison is of interest because many of the previously presented studies in using GRACE for hydrological data assimilation have neglected the existing correlation in observations (see e.g., Zaitchik et al., 2008; Houborg et al., 2012; Li et al., 2012; Tangdamrongsub et al., 2015; Sun et al., 2015; Kumar et al., 2016).

\section{FIGURE 10}

It can be seen that locally applying the GRACE observations effectively reduces errors for every grid resolution considered in comparison to the uncorrelated observation assumption. This, however, is more obvious for higher spatial resolution (e.g., $3^{\circ}$ and higher) where a large difference between the assimilation results with and without the application of LA can be found. Although LA mathematically solves the inverse problem for using $1^{\circ}$ gridded GRACE TWS 
data and associated error covariance (cf. Table 1) in the filtering process, this spatial resolution results in a larger error in comparison to the other scenarios. From Section 2.1, we know that truncating and smoothing procedures cause losing a part of GRACE data, especially in higher frequencies. Rescaling such a data into $1^{\circ}$ spatial resolution results in an error in gridded GRACE TWS and correspondingly in the assimilation result (cf. Figure 10). Figure 10 shows that increasing the spatial resolution results in a better estimation when LA is not applied. This error reduction by using a higher spatial resolution is also true when LA is applied but only to the point of $3^{\circ}$. After this point, errors start increasing, which can be explained by fewer observations used leading to less information content to be transferred to model states. The application of LA, however, reduces the error for all spatial resolutions while in an absolute sense, the smallest errors are obtained for $3^{\circ}$. Interestingly, this spatial resolution is about the spatial resolution that GRACE can resolve.

More detailed results are proposed in Figure 11 and Table 2 in terms of RMSE and correlation analysis. As mentioned before, first, assimilation time series are interpolated at the location of the groundwater in-situs and then, their anomalies are calculated. A similar procedure is also applied to achieve assimilation time series over the soil moisture in-situ stations. Then for all stations, RMSE and correlation factor between assimilation results (for various scenarios) and in-situ measurements are calculated and their averages are used for assessment. Note that considering the difference between W3RA estimations (column water storage) and the OzNet measurements (volumetric soil moisture), only correlation analysis is assumed for assessing results against soil moisture in-situ data. The reason for this refers to the fact that converting model outputs (with unit 'mm') into volumetric units may introduce a bias (Renzullo et al., 2014). Estimated correlations between assimilation results and OzNet soil moisture (an average correlation for the total soil column; Figure 11a) as well as groundwater in-situ level data (Figure 11b) demonstrate the ability of LA in dealing with GRACE data. Also, both correlation analyses show that applying GRACE TWS with $3^{\circ}$ leads to closer results to the in-situ measurements.

\section{FIGURE 11}

TABLE 2

$$
\text { Based on the results in Table 2, all the results successfully improved the model estimation }
$$


of water storage variation. Applying LA in data assimilation leads up to $24.73 \%$ (13\% average) better estimations in comparison to the non-correlated assumption. This proves the importance of using local data assimilation for incorporating GRACE data into the hydrological model. We know from Eicker et al. (2014) that spatial upscaling of GRACE data to coarser resolutions (e.g., $5^{\circ}$ ) can significantly stabilize the assimilation process leading to more reliable results, however, LA can improve the results not only for these resolutions but also for smaller grid sizes (cf. Table 2).

It can be seen from Table 2 that using gridded TWS observation with $3{ }^{\circ}$ shows the best performance in terms of RMSE. Although there is no rank deficiency in using the full error covariance matrix for this grid resolution, local implementation of the assimilation process helps to improve the agreement with the in-situ measurements. The reason why LA does not have a similar impact on finer spatial resolutions, especially for a 10 resolution in comparison to $3^{\circ}$, could be due to the characteristic of GRACE $\mathrm{L} 2$ product as a degree limited data, e.g., truncated spherical harmonics sets. An interesting observation from Table 2 refers to the results of using GRACE TWS for a $2^{\circ}$ spatial resolution. Considering Table 1, employing the $2^{\circ}$ grid resolution causes a rank deficiency in covariance matrix leading to the unstable data assimilation. LA successfully solves this problem and significantly improves the results with a better performance ( $57.87 \%$ improvement). Fewwer observations incorporated in the assimilation on a basin scale and for $5^{\circ}$ resolution in comparison to the other spatial scales (e.g., $3^{\circ}$ ) leads to a weaker performance for these two cases.

\section{Conclusion}

The global time variable terrestrial water storage (TWS) data from the Gravity Recovery And Climate Experiment (GRACE) has provide an important opportunity for a hydrological model adjustment. In this study, we assessed the performance of local analysis (LA) method in accounting for the existing correlation in GRACE data and improving its effect on model states. To this end, we assimilated the GRACE-derived TWS changes into the World-Wide Water Resources Assessment system (W3RA) during 2003 to 2012 using Square Root Analysis (SQRA) filtering technique. LA was applied to (i) solve the mathematical problem of using correlated data for assimilation especially when the observation spatial resolution is high (e.g., $1^{\circ}$ gridded TWS), and (ii) improve the assimilation results using GRACE TWS data for different 
spatial resolutions ( $1^{\circ}$ to $5^{\circ}$ and a basin scale). The observations were applied for a 5 -day temporal scale and for 5 different grid resolutions to monitor the impact of LA on each scenario.

The results showed that implementing LA successfully reduced data assimilation errors for all the cases $(54.08 \%$ on average). This improvement is larger for the cases with smaller grid sizes along with the higher error correlations. LA addressed the rank deficiency problem in using the full information from the error covariance matrix for a higher spatial resolution of GRACE TWS data (e.g., $1^{\circ}$ ). This, to the best of our knowledge, for the first time, allowed us to be able to apply GRACE TWS considering spatial error correlation information at finer spatial resolutions (e.g., $1^{\circ}$ and $2^{\circ}$ ) for the hydrological data assimilation. LA also improved the assimilation results at all grid resolutions and basin scale especially in comparison to using noncorrelated observations ( $13.76 \%$ average). This highlights the great potential of LA in different scenarios for improved data assimilation. The best performance with $67.84 \%$ improvement was found with the application of GRACE data in assimilation with $3^{\circ}$ spatial resolution. Overall, the importance of the application of LA in hydrological data assimilation is: (1) stabilising the assimilation of GRACE TWS observation using its full error covariance for finer spatial resolutions (e.g., $1^{\circ}$ and $2^{\circ}$ ), and (2) improving the results for all the spatial grid sizes without the assumption of white noise. This study offered a method to deal with the GRACE error covariance matrix during data assimilation, however, further assessment needs to be undertaken to examine other potential methods like inflation of the observation error variances and circulant approximation.

\section{Acknowledgement}

We would like to thank professor Harrie-Jan Hendricks-Franssen, the associate editor of Advances in Water Resources, and Dr. Manuela Girotto for their useful comments, which contributed to the improvement of this study. M. Khaki is grateful for the research grant of Curtin International Postgraduate Research Scholarships (CIPRS)/ORD Scholarship provided by Curtin University (Australia). This work is a TIGeR publication. 


\section{References}

\section{References}

Alsdorf, D.E., Rodriguez, E., Lettenmaier, D.P., 2007. Measuring surface water from space. Rev. Geophys., 45, RG2002, doi:10.1029/2006RG000197.

Anderson, J.L., Anderson, S.L., 1999. A Monte Carlo implementation of the nonlinear filtering problem to produce ensemble assimilations and forecasts. Mon Weather Rev 127:27412758.

Anderson, J., 2001. An Ensemble Adjustment Kalman Filter for/Data Assimilation. Mon. Wea. Rev., 129, 28842903, http://dx.doi.org/10.1175/15200493(2001)129¡2884:AEAKFF ¿2.0.CO;2.

Anderson, M.C., Norman, J.M., Mecikalski, J.R., Otkin, J.A., Kustas, W.P., 2007. A climatological study of evapotranspiration and moisture stress across the continental United States based on thermal remote sensing: 1. Model formulation. J. Geophys. Res. 112 (D10117). http://dx.doi.org/10.1029/2006JD007506.

Bennett, A. F., 2002. Inverse Modeling of the Ocean and Atmosphere. 234 pp., Cambridge Univ. Press, New York.

Bergemann, K., Reich, S., 2010. A localization technique for ensemble Kalman filters. Q. J. R. Meteorol. Soc. 136: 701707.

Berger, H., Forsythe, M., 2004. Satellite wind superobbing. Met Office Forecasting Research Technical Report, 451

Bertino, L., Evensen G., Wackernagel, H., 2003. Sequential Data Assimilation Techniques in Oceanography. International Statistical Review, Vol. 71, No. 2, pp. 223-241.

Brocca, L., Melone, F., Moramarco, T., Wagner, W., Naeimi, V., Bartalis, Z., Hasenauer, S., 2010. Improving runoff prediction through the assimilation of the ASCAT soil moisture product, Hydrol. Earth Syst. Sci., 14, 18811893, http://dx.doi.org/10.5194/hess-14-18812010.

Burgers, G., van Leeuven, P.J., Evensen, G., 1998. Analysis scheme in the ensemble Kalman filter, Mon. Wea. Rev., 126, 17191724. 
Chen, J.L., Wilson, C.R., Famiglietti, J.S., Rodell, M., 2007. Attenuation effect on seasonal basin-scale water storage changes from GRACE time-variable gravity. Journal of Geodesy, 81, 4, 237245. http://dx.doi.org/10.1007/s00190-006-0104-2.

Chen, J.L., Wilson, C.R., Tapley, B.D., 2013. Contribution of ice sheet and mountain glacier melt to recent sea level rise. Nat. Geosci., 6, 549552, http://dx.doi.org/10.1038/ngeo1829.

Cheng, M.K., Tapley, B.D., 2004. Variations in the Earth's oblateness during the past 28 years. Journal of Geophysical Research, Solid Earth, 109, B09402. http://dx.doi.org/10.1029/2004JB003028.

Clark, M.P., Rupp, D.E., Woods, R.A., Zheng, X., Ibbitt, R.P., Slater, A.G., 2008. Data assimilative modeling investigation of Gulf Stream Warm Core Ring interaction with continental shelf and slope circulation, Hydrological data assimilation with the ensemble Kalman filter: Use of streamflow observations to update states in a distributed hydrological model. Advances in Water Resources, 31, 10, 1309-1324, ISSN 0309-1708, http://dx.doi.org/10.1016/j.advwatres.2008.06.005.

Coumou, D., Rahmstorf, S., 2012. A decade of weather extremes. Nature Clim. Change, 2(7), 491-496.

Crow, W., Wood, E., 2003. The assimilation of remotely sensed soil brightness temperature imagery into a land surface model using ensemble filtering: A case study based on ESTAR measurements during SGP97. Adv. Water Res., 26, 137149.

Dando, M. L., Thorpe, A. J., Eyre, J. R., 2007. The optimal density of atmospheric sounder observations in the Met Office NWP system. Q.J.R.Meteorol.Soc., 133:19331943.

Eicker, A., Schumacher, M., Kusche, J., Dll, P., Mller-Schmied, H., 2014. Calibration/data assimilation approach for integrating GRACE data into the WaterGAP global hydrology model(WGHM) using an ensemble Kalman filter: first results. SurvGeophys, 35(6):12851309. http://dx.doi.org/10.1007/s10712-014-9309-8.

Elbern, H., Schmidt, H., 2001. Ozone episode analysis by fourdimensional variational chemistry data assimilation. J. Geophys. Res., 106, 35693590.

Evensen, G., 2003. The ensemble Kalman filter: Theoretical formulation and practical inplementation. Ocean Dynamics, 53, 343367, http://dx.doi.org/10.1007/s10236-003-0036-9. 
Evensen, G., 2004. Sampling strategies and square root analysis schemes for the EnKF. Ocean Dyn. 54(6), 539-560.

Evensen, G., 2007. Data Assimilation: The Ensemble Kalman Filter. Springer, 279 pp.

Famiglietti, J.S., Rodell, M., 2013. Water in the balance. Science, 340, 6138, 1300-1301. http://dx.doi.org/10.1126/science.1236460.

Forootan, E., Rietbroek, R., Kusche, J., Sharifi, M.A., Awange, J., Schmidt, M., Omondi, P., Famiglietti, J., 2014. Separation of large scale water storage patterns over Iran using GRACE, altimetry and hydrological data. Journal of Remote Sensing of Environment, 140, 580-595. http://doi.org/10.1016/j.rse.2013.09.025

Forootan, E., Khandu, Awange, J., Schumacher, M., Anyah, R., van Dijk, A., Kusche, J., 2016. Quantifying the impacts of ENSO and IOD on rain gauge and remotely sensed precipitation products over Australia. Remote Sensing of Environment,172, Pages 50-66, http://dx.doi.org/10.1016/j.rse.2015.10.027.

Garner, T.W., Wolf, R.A., Spiro, R.W. , Thomsen, M.F., 1999. First attempt at assimilating data to constrain a magnetospheric model. J. Geophys. Res., 104(A11), 2514525152, http://dx.doi.org/10.1029/1999JA900274.

Girotto, M., De Lannoy, G.J., Reichle, R.H., Rodell, M. 2016. Assimilation of gridded terrestrial water storage observations from GRACE into a land surface model. Water Resources Research, 52(5), 4164-4183.

Girotto, M., De Lannoy, G.J., Reichle, R.H., Rodell, M., Draper, C., Bhanja, S.N., Mukherjee, A. 2017. Benefits and Pitfalls of GRACE Data Assimilation: a Case Study of Terrestrial Water Storage Depletion in India. Geophysical Research Letters.

Giustarini, L/, Matgen, P., Hostache, R., Montanari, M., Plaza, D., Pauwels, V.R.N., De Lannoy, G.J.M., De Keyser, R., Pfister, L., Hoffmann, L., Savenije, H.H.G., 2011. Assimilating SAR-derived water level data into a hydraulic model: a case study. Hydrol. Earth Syst. Sci., 15, 23492365, http://dx.doi.org/10.5194/hess-15-2349-2011.

Hamill, T.M., Snyder, C. (2002); Using improved background-error covariances from an ensemble Kalman filter for adaptive observations. Mon Wea Rev 130:15521572. http://dx.doi.org/10.1175/1520-0493(2002)130;1552:UIBECF ¿2.0.CO;2. 
Hoteit, I., Luo, X., Pham, D.T., 2012. Particle Kalman Filtering: A Nonlinear Bayesian Framework for Ensemble Kalman Filters. Monthly Weather Review, 140:2, 528-542.

Houborg, R., Rodell, M., Li, B., Reichle, R.H., Zaitchik, B.F., 2012. Drought indicators based on model-assimilated Gravity Recovery and Climate Experiment (GRACE) terrestrial water storage observations. Water Resour Res 48:W07525. http://dx.doi.org/10.1029/2011WR011291.

Houtekamer, P.L., 1995. The construction of optimal perturbations. Mon Weather Rev $123: 28882898$.

Houtekamer, P.L., Mitchell, H.L., 1998. Data assimilation using an ensemble Kalman filter technique. Mon. Wea. Rev., 126, 796811.

Houtekamer, P.L., Mitchell, H.L., 2001. A Sequential Ensemble Kalman Filter for Atmospheric Data Assimilation. Mon. Wea. Rev., 129:1, 123-137.

Huffman, G., Bolvin, D., 2012. TRMM and other data precipitation data set documentation. Mesoscale Atmospheric Processes Laboratory, NASA Goddard Space Flight Center and Science Systems and Applications, Inc.

Huntington, T.G., 2006. Evidence for intensification of the global water cycle: Review and synthesis. J. Hydrol., 319(14), 8395

Jardak, M., Navon, I.M. Zupanski, M., 2007. Comparison of sequential data assimilation methods for the KuramotoSivashinsky equation. International journal for numerical methods in fluids, Volume 62, Issue 4, 374402, http://dx.doi.org/10.1002/fld.2020.

Jazwinski, A.H., 1970. Stochastic Processes and Filtering Theory. Academic Press, 376 pp. Jones, D.A., Wang, W., Fawcett, R., Grant, I., 2007. Climate data for the Australian water availability project. In: Australian Water Availability Project Milestone Report. Bur. Met., Australia, 37pp.

Kalnay, E., 2003. Atmospheric modelling, data assimilation and predictability. Cam-

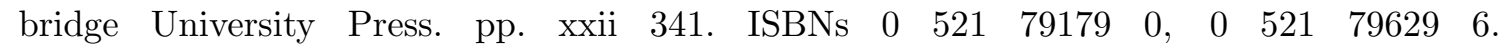
http://dx.doi.org/10.1256/00359000360683511. 
Keppenne, C.L., 2000. Data assimilation into a primitive-equation model with a parallel ensemble Kalman filter. Mon Weather Rev 128:19711981.

Keppenne, C.L., Rienecker, M., 2002. Initial testing of a massively parallel ensemble Kalman filter with the poseidon isopycnal ocean general circulation model. Mon Weather Rev $130: 29512965$.

Khaki, M., Hoteit, I., Kuhn, M., Awange, J., Forootan, E., van Dijk, A.I.J.M., Schumacher, M., Pattiaratchi, C., 2017. Assessing sequential data assimilation techniques for integrating GRACE data into a hydrological model, Advances in Water Resources, Volume 107, Pages 301-316, ISSN 0309-1708, http://dx.doi.org/10.1016/j.advwatres.2017.07.001.

Klees, R., Revtova, E.A., Gunter, B.C., Ditmar, P., Oudman, E., Winsemius, H.C., 2008. The design of an optimal filter for monthly GRACE gravity models. Geophysical Journal International, 175, 2, 417-432, http://dx.doi.org/10.1111/j.1365-246X.2008.03922.x.

Kumar, S.V., Peters-Lidard, C.D., Mocko, D., Reichle, R.H., Liu, Y., Arsenault, K.R., Xia, Y., Ek, M., Riggs, G., Livneh, B., Cosh, M., 2014. Assimilation of remotely sensed soil moisture and snow depth retrievals for drought estimation, Journal of Hydrometeorology, 15, 2446-2469, http://dx.doi.org/10.1175/JHM-D-13-0132.1.

Kumar, S.V., Peters-Lidard, C.D., Santanello, J.A., Reichle, R.H., Draper, C.S., Koster, R.D., Nearing, G., Jasinski, M.F., 2015. Evaluating the utility of satellite soil moisture retrievals over irrigated areas and the ability of land data assimilation methods to correct for unmodeled processes, Hydrology and Earth System Sciences, 19, 4463-4478, http://dx.doi.org/10.5194/hess-19-4463-2015.

Kumar, S., Zaitchik, B., Peters-Lidard, C., Rodell, M., Reichle, R., Li, B., Jasinski, M., Mocko, D., 2016. Assimilation of Gridded GRACE Terrestrial Water Storage Estimates in the North American Land Data Assimilation System. J. Hydrometeor., 17, 19511972, http://dx.doi.org/10.1175/JHM-D-15-0157.1.

Kusche, J., 2007. Approximate decorrelation and non-isotropic smoothing of time-variable GRACE-type gravity field models. J. Geod., 81, 733739.

Kusche, J., Klemann, V., Bosch, W., 2012. Mass distribution and mass transport in the Earth system. Journal of Geodynamics, 59-60, 1-8. http://doi.org/10.1016/j.jog.2012.03.003. 
Lahoz, W.A., Geer, A.J., Bekki, S., Bormann, N., Ceccherini, S., Elbern, H., Errera, Q., Eskes, H.J., Fonteyn, D., Jackson, D.R., Khattatov, B., 2007. The Assimilation of Envisat data (ASSET) project. Atmos. Chem. Phys., 7, 1773 - 1796.

Li, B., Rodell, M., Zaitchik, B.F., Reichle, R.H., Koster, R.D., van Dam, T.M., 2012. Assimilation of GRACE terrestrial water storage into a land surface model: Evaluation and potential value for drought monitoring in western and central Europe. Journal of Hydrology, http://dx.doi.org/10.1016/j.jhydrol.2012.04.035.

Liu, Z.Q., Rabier., F., 2003. The potential of high-density observations for numerícal weather prediction: A study with simulated observations. Q.J.R.Meteorol.\$oc., 129, 30133035.

Liu, Y., Weerts, A.H., Clark, M., Hendricks Franssen, H.-J., Kumar, S., Moradkhani, H., Seo, D.-J., Schwanenberg, D., Smith, P., van Dijk, A.I.J.M., van Velzen, N., He, M., Lee, H., Noh, S.J., Rakovec, O., and Restrepo, P., 2012. Advancing data assimilation in operational hydrologic forecasting: progresses, challenges, and emerging opportunities. Hydrol. Earth Syst. Sci., 16, 3863-3887, http://dx.doi.org/10.5194/hess-16-3863-2012.

Liu, Y., Peters-Lidard, C.D., Kumar, S., Foster, J.L., Shaw, M., Tian, Y., Fall, G.M., 2013. Assimilating satellitebased snow depth and snow cover products for improving snow predictions in Alaska, Adv. Water Res., 54, 208227, http://dx.doi.org/10.1016/j.advwatres.2013.02.005.

Longuevergne, L., Scanlon, B.R., Wilson, C.R., 2010. GRACE Hydrological estimates for small basins: Evaluating processing approaches on the High Plains Aquifer, USA. Water Resources Research, 46, 11, W11517. http://dx.doi.org/10.1029/2009WR008564.

Longuevergne, L., Wilson, C.R., Scanlon, B.R., Crtaux, J.F., 2013. GRACE water storage estimates for the Middle East and other regions with significant reservoir and lake storage. Hydrol. Earth Syst. Sci., 17, 48174830, http://dx.doi.org/10.5194/hess-17-4817-2013.

Mayer-Gürr, T., Zehentner, N., Klinger, B., Kvas, A., 2014. ITSG-Grace2014: a new GRACE gravity field release computed in Graz. - in: GRACE Science Team Meeting (GSTM). Potsdam am: 29.09.2014.

Mitchell, H.L., Houtekamer, P.L., 2000. An adaptive ensemble Kalman filter. Mon. Wea. Rev. $128,416433$. 
Mitchell, H.L., Houtekamer, P.L., Pellerin, G., 2002. Ensemble size, balance, and model-error representation in an ensemble Kalman filter. Mon Weather Rev 130:27912808.

Moradkhani, H., Hsu, K., Hong, Y., Sorooshian, S., 2006. Investigating the impact of remotely sensed precipitation and hydrologic model uncertainties on the ensemble streamflow forecasting. Geophys. Res. Lett. 33, L12107.

Munier, S., Aires, F., Schlaffe, S., Prigent, C., Papa, F., Maisongrande, P., Pan, M., 2014. Combining data sets of satellite-retrieved products for basin-scale water balance study: 2 . Evaluation on the Mississippi Basin and closure correction model. Journal of Geophysical Research: Atmospheres, 119, 12,100-12,116, http://dx.doi.org/10.1002/2014JD021953.

Neal, J., Schumann, G., Bates, P., Buytaert, W., Matgen, P., Pappenberger, F., 2009. A data assimilation approach to discharge esti- mation from space. Hydrol. Process., 23, 36413649.

Oke, P.R., Sakov, P., Corney, S.P., 2007. Impacts of localisation in the EnKF and EnOI: experiments with a small model. Ocean Dyn. 57, 3245.

Oke, P.R., Brassington, G.B., Griffin, D.A., Schiller, A., 2008. The Bluelink Ocean Data Assimilation System (BODAS). Ocean Modelling, 21, 4670, http://dx.doi.org/10.1016/j.ocemod.2007.11.002.

Ott, E., Hunt, B.R., Szunyogh, I., Zimin, A.V., Kostelich, E.J., Corazza, M., Kalnay, E., Patil, D.J., Yorke, J.A., 2004. A loeal ensemble Kalman Filter for atmospheric data assimilation. Tellus, 56A: 415-428

Reager, J.T., Thomas, A.C., Sproles, E.A., Rodell, M., Beaudoing, H.K., Li, B., Famiglietti, J.S., 2015. Assimilation of GRACE Terrestrial Water Storage Observations into a Land Surface Model for the Assessment of Regional Flood Potential. Remote Sens., 7, 14663-14679.

Renzullo, L.J., Van Dijk, A.I.J.M., Perraud, J.M., Collins, D., Henderson, B., Jin, H., Smith, A.B., McJannet, D.L., 2014. Continental satellite soil moisture data assimilation improves root-zone moisture analysis for water resources assessment. J. Hydrol., 519, 27472762. http://dx.doi.org/10.1016/j.jhydrol.2014.08.008.

Reichle, R. H., McLaughlin, D. B., Entekhabi, D., 2002. Hydrologic Data Assimilation with the Ensemble Kalman Filter. Mon. Wea. Rev. 130, 103114, http://dx.doi.org/10.1175/15200493(2002)130;0103:HDAWTE;2.0.CO;2. 
Reichle, R.H., Crow, W.T., Keppenne, C.L., 2008. An adaptive ensemble Kalman filter for soil moisture data assimilation, Water Resour. Res., 44, W03423, http://dx.doi.org/10.1029/2007WR006357.

Reichle, R.H., Kumar, S.V., Mahanama, S.P.P., Koster, R.D., Liu, Q., 2010. Assimilation of satellite-derived skin temperature observations into land surface models, Journal of Hydrometeorology, 11, 1103-1122, http://dx.doi.org/10.1175/2010JHM1262.1.

Reichle, R.H., De Lannoy, G.J., Forman, B.A., Draper, C.S., Liu, Q., 2013. Cơnnecting satellite observations with water cycle variables through land data assimilation. Examples using the NASA GEOS-5 LDAS, in The Earths Hydrological Cycle, pp. 577606, Springer, Netherlands, http://dx.doi.org/10.1007/978-94-017-8789-5_6.

Rodell, M., Houser, P.R., Jambor, U., Gottschalick, J., Mitchell, K., et al. (2004). The Global Land Data Assimilation System, Bull. Am. Meteorol, Soc. 85, 381394.

Rodell, M., Chen, J., Kato, H., Famiglietti, J.S., Nigro, J., Wilson, C.R., 2007. Estimating groundwater storage changes in the Mississippi River basin (USA) using GRACE. Hydrogeol. J., 15, 159166.

Rodgers, C.D., 2000. Inverse Methods for Atmopsheric Sounding: Theory and Practice. World Scientific, Singapore.

Sakov, P., Oke, P.R., 2008. A deterministic formulation of the ensemble Kalman filter: an alternative to ensemble square root filters. Tellus 60A, 361371.

Schmidt, R., Petrovic, S., Gntner, A., Barthelmes, F., Wnsch, J., Kusche, J., 2008. Periodic components of water storage changes from GRACE and global hydrology models. J. Geophys. Res., 113, B08419, http://dx.doi.org/10.1029/2007JB005363.

Schumacher, M., Kusche, J., Dll, P., 2016. A systematic impact assessment of GRACE error correlation on data assimilation in hydrological models. J Geodesy. http://dx.doi.org/10.1007/s00190-016-0892-y.

Schunk, R.W., Scherliess, L., Sojka, J.J., Thompson, D.C., 2004. USU global ionospheric data assimilation models, Atmospheric and Environmental Remote Sensing Data Processing and Utilization: an End-to-End System Perspective. (ed. H.-L. A. Huang and H. J. Bloom), Proc. of SPIE, 5548, 327-336, http://dx.doi.org/10.1117/12.562448. 
Seo, D.J., Koren, V., Cajina, N., 2003. Real-time variational assimilation of hydrologic and hydrometeorological data into operational hydrologic forecasting. J. Hydrometeorol., 4, 627641.

Seoane, L., Ramillien, G., Frappart, F., Leblanc, M., 2013. Regional GRACE-based estimates of water mass variations over Australia: validation and interpretation. Hydrol. Earth Syst. Sci., 17, 4925-4939, http://dx.doi.org/10.5194/hess-17-4925-2013.

Shannon, C.E., Weaver, W., 1949. The Mathematical Theory of Communication. University of Illinois Press, Urbana.

Sheffield, J., Goteti, G., Wood, E.F., 2006. Development of a 50-yearhigh-resolution global dataset of meteorological forcings for land surfacemodeling. J. Clim., 19(13), 3088311.

Smith, A.B., Walker, J.P., Western, A.W., Young, R.I., Ellett, K.M., Pipunic, R.C., Richter, H., 2012. The Murrumbidgee soil moisture monitoring network data set. Water Resour. Res. 48 (7), 16. http://dx.doi.org/10.1029/2012WR011976.

Stewart, L.M., Dance, S.L., Nichols, N.K., 2008. Correlated observation errors in data assimilation. Int. J. Numer. Meth. Fluids, 56: 15211527, http://dx.doi.org/10.1002/fld.1636.

Stone, J.V., (2004). Independent component analysis: a tutorial introduction. MIT Press, London.

Sun, Q., Xie, Z., Tian, X., 2015. GRACE terrestrial water storage data assimilation based on the ensemble four-dimensional variational method PODEn4DVar: Method and validation. Sci. China Earth Sci. 58: 371. http://dx.doi.org/10.1007/s11430-014-4978-1.

Swenson, S., Wahr,J., 2002. Methods for inferring regional surface-mass anomalies from Gravity Recovery and Climate Experiment (GRACE) measurements of time-variable gravity. Journal of Geophysical research, 107, B9, 2193. http://dx.doi.org/10.1029/2001JB000576.

Swenson, S., Wahr, J., 2006. Post-processing removal of correlated errors in GRACE data. Geophysical Research Letters, 33, L08402. http://dx.doi.org/10.1029/2005GL025285.

Swenson, S., Chambers, D., Wahr, J., 2008. Estimating geocentervariations from a combination of GRACE and ocean model output. Journal of Geophysical research, 113, B08410. http://dx.doi.org/10.1029/2007JB005338. 
Syed, T.H., Famigletti, J.S., Chen, J., Rodell, M., Seneviratne, S.I., Viterbo, P., Wilson, C.R., 2005. Total basin discharge for the Amazon and Mississippi River basins from GRACE and a landatmosphere water balance. Geophysical Research Letters, 32, L24404. http://dx.doi.org/10.1029/2005GL024851

Tangdamrongsub, N., Steele-Dunne, S.C., Gunter, B.C., Ditmar, P.G., Weerts, A.H., 2015. Data assimilation of GRACE terrestrial water storage estimates into a regional hydrological model of the Rhine River basin. Hydrol. Earth Syst. Sci., 19, 2079-2100, http://dx.doi.org/10.5194/hess-19-2079-2015.

Tapley, B.D., Bettadpur, S., Watkins, M., Reigber, C., 2004. The gravity recovery and climate experiment: mission overview and early results. Geophys Res Lett 31:L09607. http://dx.doi.org/10.1029/2004GL019920.

Thomas, A.C., Reager, J.T., Famiglietti, J.S., Rodell, M., 2014. A GRACE-based water storage deficit approach for hydrological drought characterization. Geophys. Res. Lett., 41, 15371545.

Tippett, M.K., Anderson, J.L., Bishop, C.H., Hamill, T.M., Whitaker, J.S., 2003. Ensemble square root filters. Mon. Weath. Rev., 131, 148590.

Tregoning, P., McClusky, S., van Dijk, A.I.J.M., Crosbie, R.S., Pea-Arancibia, J.L., 2012. Assessment of GRACE Satellites for Groundwater Estimation in Australia. National Water Commission, Canberra, 82 pp.

van Dijk, A.I.J.M., 2010. The Australian Water Resources Assessment System: Technical Report 3, Landscape model (version 0.5) Technical Description. CSIRO: Water for a Healthy Country National Research Flagship.

van Dijk, A.I.J.M., Pea-Arancibia, J.L., Wood, E.F., Sheffield, J., Beck, H.E., 2013. Global analysis of seasonal streamflow predictability using an ensemble prediction system and observations from 6192 small catchments worldwide. Water Resour. Res., 49, 27292746, http://dx.doi.org/10.1002/wrcr.20251.

van Dijk, A.I.J.M., Renzullo, L.J., Wada Y, Tregoning, P., 2014. A global water cycle reanalysis (2003-2012) merging satellite gravimetry and altimetry observations with a hydrological multi-model ensemble. Hydrol Earth Syst Sci 18:29552973. http://dx.doi.org/10.5194/hess18-2955-2014. 
van Leeuwen, P.J., Evensen, G., 1996. Data assimilation and inverse methods in terms of a probabilistic formulation. Monthly Weather Review 124, 28982913.

Vrugt, J.A., Diks, C.G., Gupta, H.V., Bouten, W., Verstraten, J.M., 2005. Improved treatment of uncertainty in hydrologic modeling: Combining the strengths of global optimization and data assimilation. Water Resour. Res, 41, W01017, http://dx.doi.org/10.1029/2004WR003059.

Vrugt, J.A., ter Braak, C.J.F., Diks, C.G.H., Schoups, G., 2013. Advancing hydrologic data assimilation using particle Markov chain Monte Carlo simulation: theory, concepts and applications. Advances in Water Resources, Anniversary Issue - 35 Years, 51, 457-478, http://dx.doi.org/10.1016/j.advwatres.2012.04.002.

Wahr, J., Molenaar, M., 1998. Time variability of the Earth's gravity field' Hydrological and oceanic effects and their possible detection using GRACE. Journal of Geophysical research, 103, B12, 30, 205-30, 229. http://dx.doi.org/10.1029/98JB02844.

Watkins, M.M., Wiese, D.N., Yuan, D.-N., Bøening, C., Landerer, F.W., 2015. Improved methods for observing Earths time variable mass distribution with GRACE using spherical cap mascons. J. Geophys. Res. Solid Earth, 120, http://dx.doi.org/10.1002/2014JB011547.

Weerts, A.H., El Serafy, G.Y.H., 2006. Particle filtering and ensemble Kalman filtering for state updating with hydrological conceptual rainfall-runoff models. Water Resour. Res., 42, W09403, http://10.1029/2005WR004093.

Widiastuti, E., 2009. Data assimilation of GRACE terrestrial water storage data into a hydrological model using the ensemble Kalman smoother: A case study of the Rhine river basin. MSc Thesis, TU Delft, Delft.

Wiese, D.N., 2015. GRACE monthly global water mass grids NETCDF RELEASE 5.0. Ver. 5.0. PO.DAAC, CA, USA. Dataset accessed [YYYY-MM-DD] at http://dx.doi.org/10.5067/TEMSC-OCL05.

Wouters, B., Bonin, J.A., Chambers, D.P., Riva, R.E. M., Sasgen, I., Wahr, J., 2014. GRACE, time-varying gravity, Earth system dynamics and climate change. Reports on Progress in Physics, 77, 11, 116801. http://dx.doi.org/10.1088/0034-4885/77/11/116801. 
Zaitchik, B.F., Rodell, M., Reichle, R.H., 2008. Assimilation of GRACE terrestrial water storage data into a land surface model: results for the Mississippi River Basin. J. Hydrometeorol 9(3):535548. http://dx.doi.org/10.1175/2007JHM951.1.

Zeng, Y., 2014. Efficient Radar Forward Operator for Operational Data Assimilation within the COSMO-model, KIT Scientific Publishing. pp. 187. ISBN 3731501287, 9783731501282.

Zhang, Y., Bocquet, M., Mallet, V., Seigneur, C., Baklanov, A., 2012. Real-time air quality forecasting, Part I: History, techniques, and current status. Atmos. Environ., 60, 632655. 


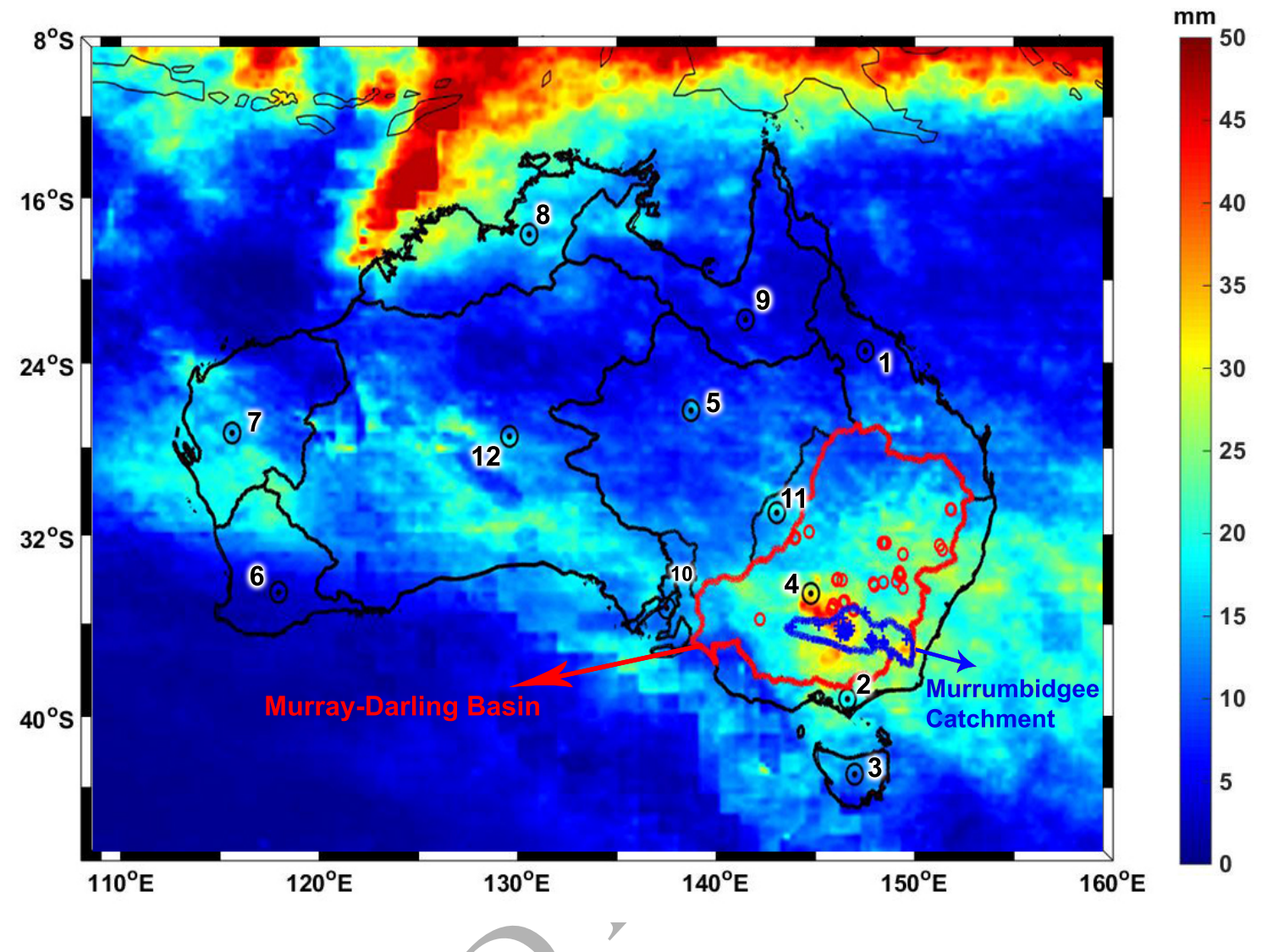

Figure 1: Overview of the study area. The black polygons indicate the twelve river basins that are considered for spatial aggregation of GRACE datà to basin scale. The red and blue polygons indicate the Murray-Darling Basin and Murrumbidgee Catchment, respectively. Data from in-situ groundwater stations (red circles) and data from the OzNet soil moisture network (blue circles) are used in these regions for independent validation of the data assimilation results. The underlaying map shows temporally averaged precipitation between 2003-2013 from TRMM-3B42 products) (Huffman et al., 2012) on a $1^{\circ} \times 1^{\circ}$ grid.

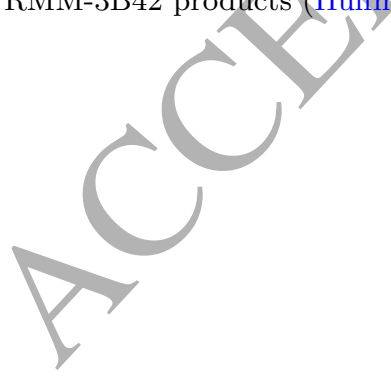




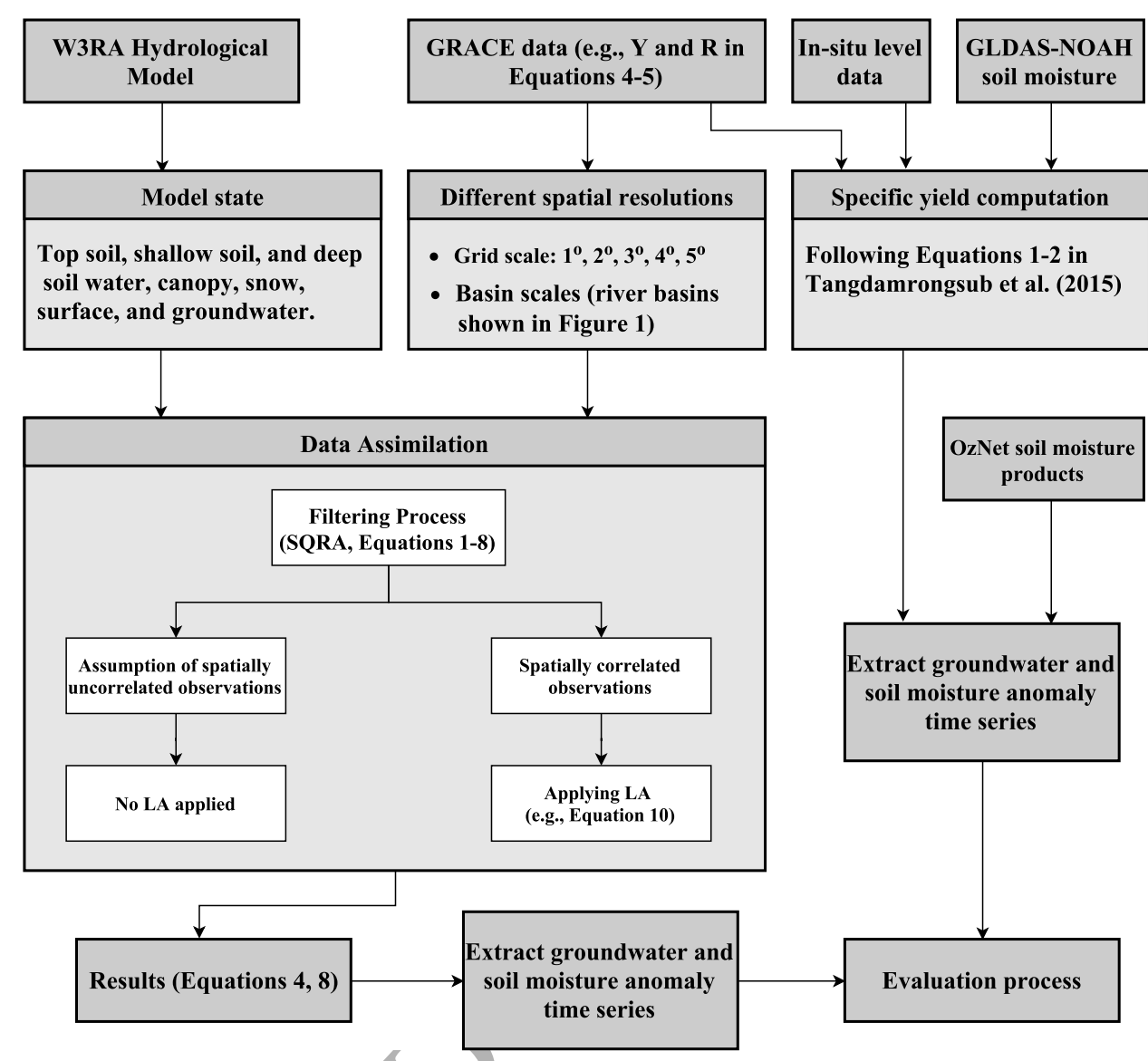

Figure 2: A schematic illustration of the data assimilation approach implemented for this study and of the considered data sets. 

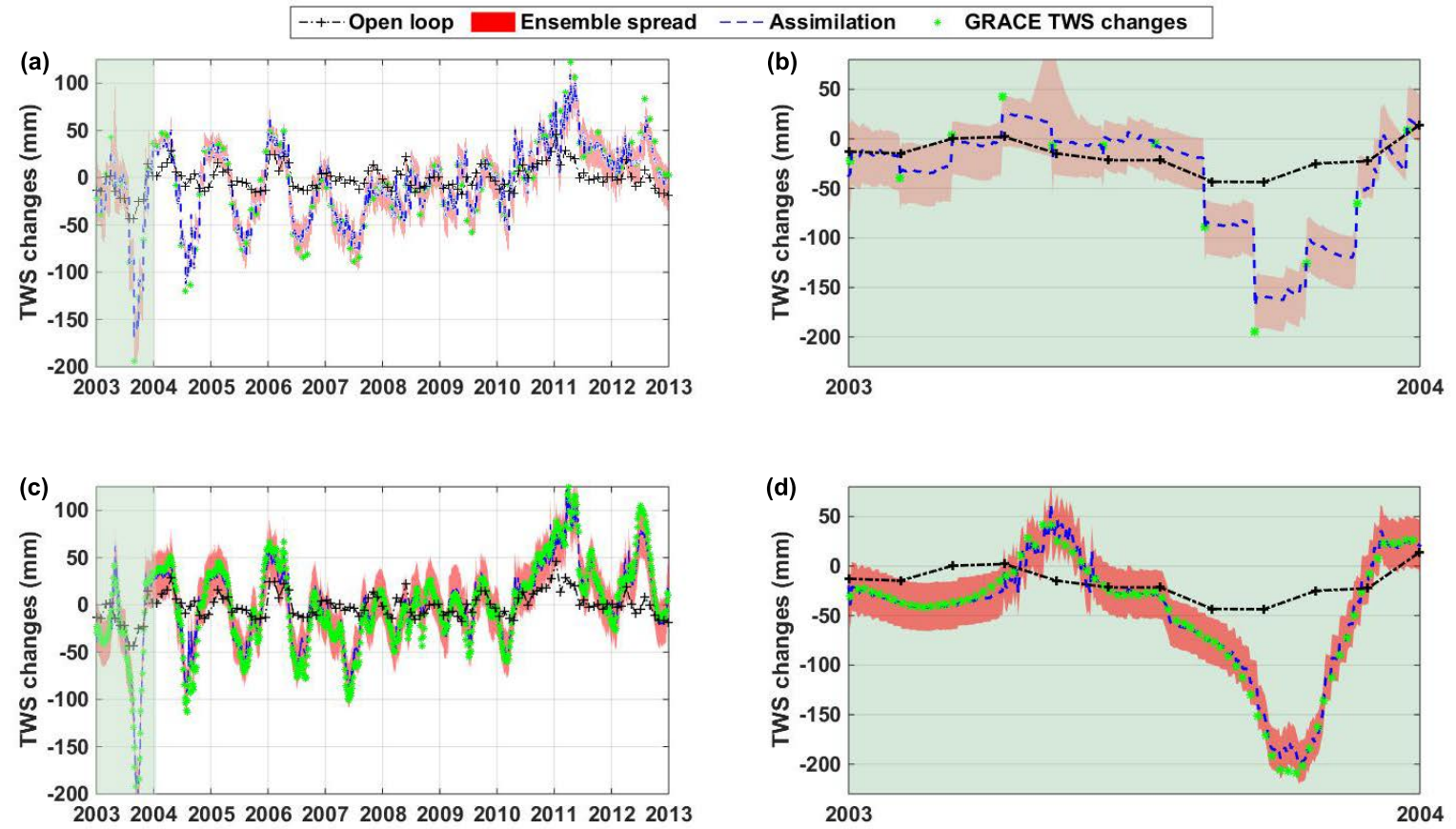

Figure 3: Comparison between the assimilated time series using the $1^{\circ}$ observations in a monthly (a) and 5-day temporal scale for an arbitrary point (c). (b) and (d) respectively magnified the green areas of (a) and (c) representing a zoom-in for one year. Ensemble spread represents the spread of the ensemble of updated TWS states. Note that we use LA to account for correlated errors in GRACE error covariance for this figure. 


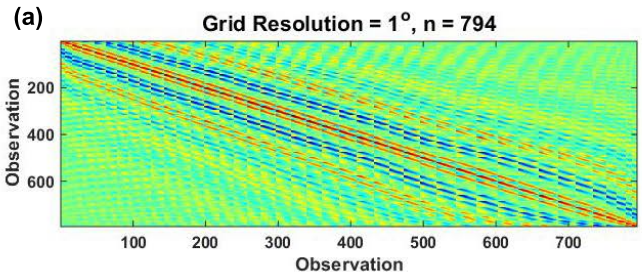

(c) Grid Resolution $=3^{\circ}, \mathrm{n}=111$

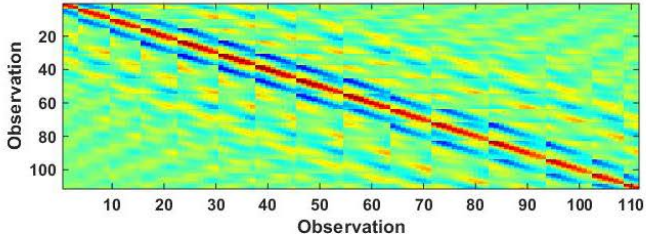

(e) Grid Resolution $=5^{\circ}, \mathrm{n}=45$

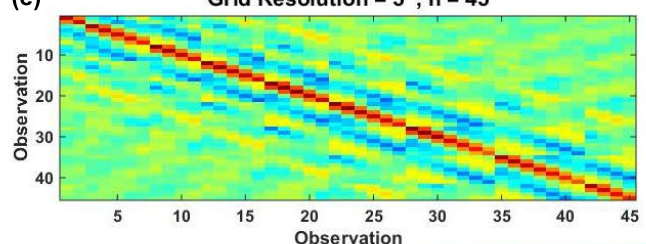

(b) Grid Resolution $=2^{\circ}, n=220$

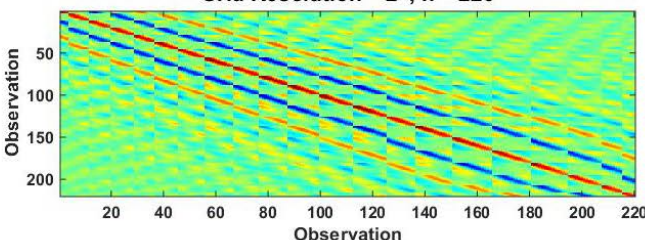

Grid Resolution $=4^{\circ}, n=67$

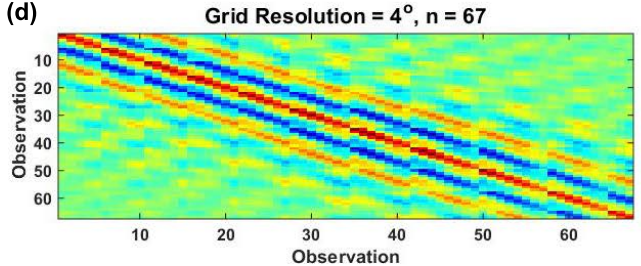

(f) Grid Resolution = Basin scale, $\mathbf{n}=\mathbf{1 2}$

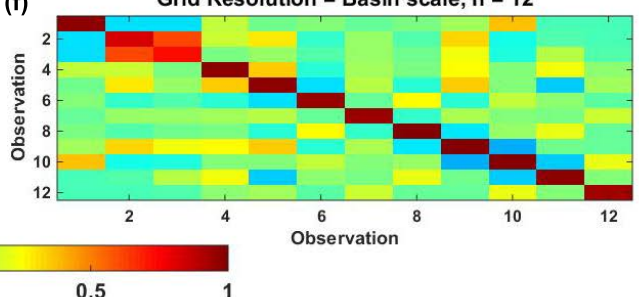

Figure 4: Correlation matrices of the GRACE observations corresponding to various spatial aggregations. Here, no localization is applied. The variable $\mathrm{n}$ refers to the number of assimilated observations. 


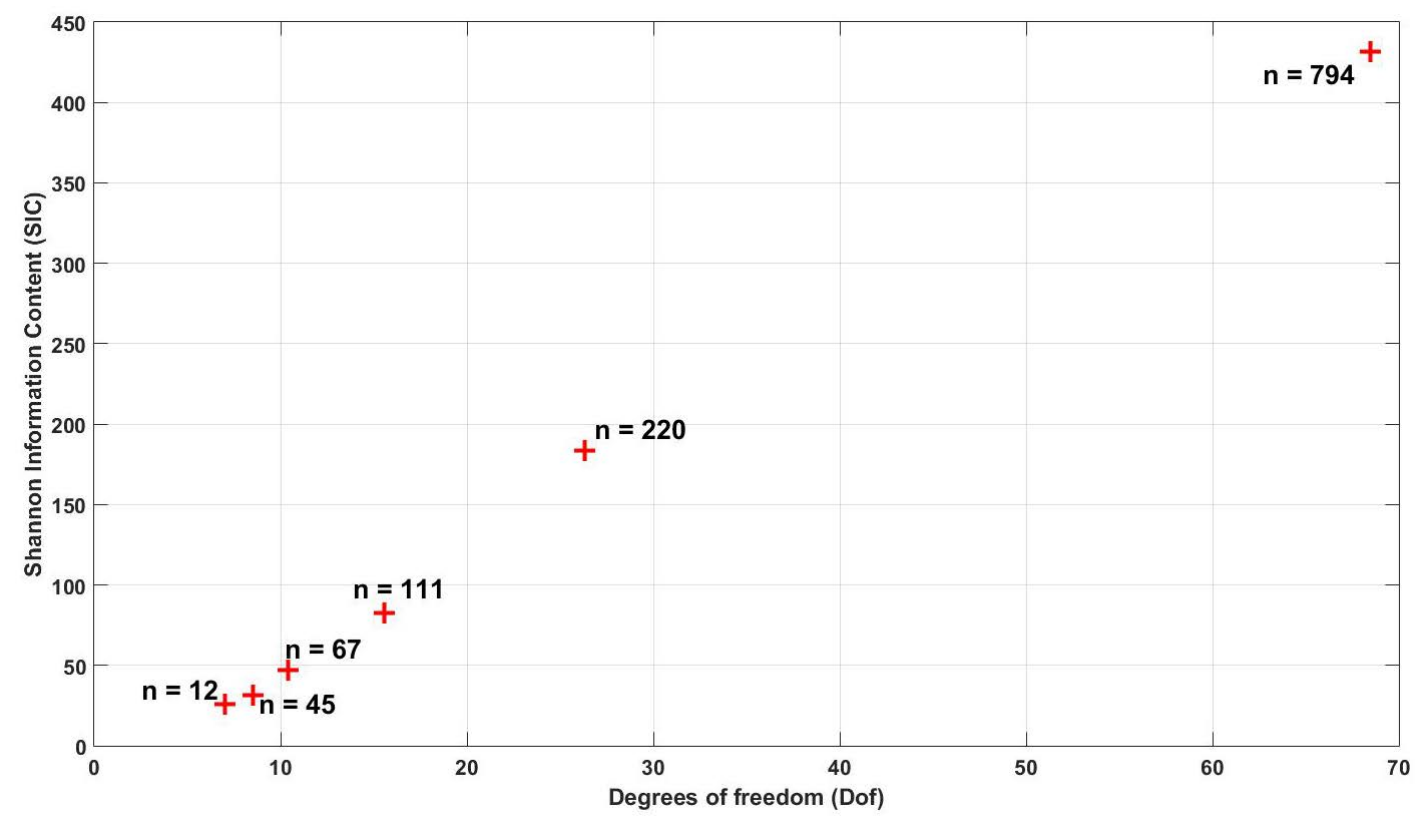

Figure 5: Shannon Information Content (SIC) and Degrees of freedom (Dof) with respect to the number of assimilated GRACE observations (n). 

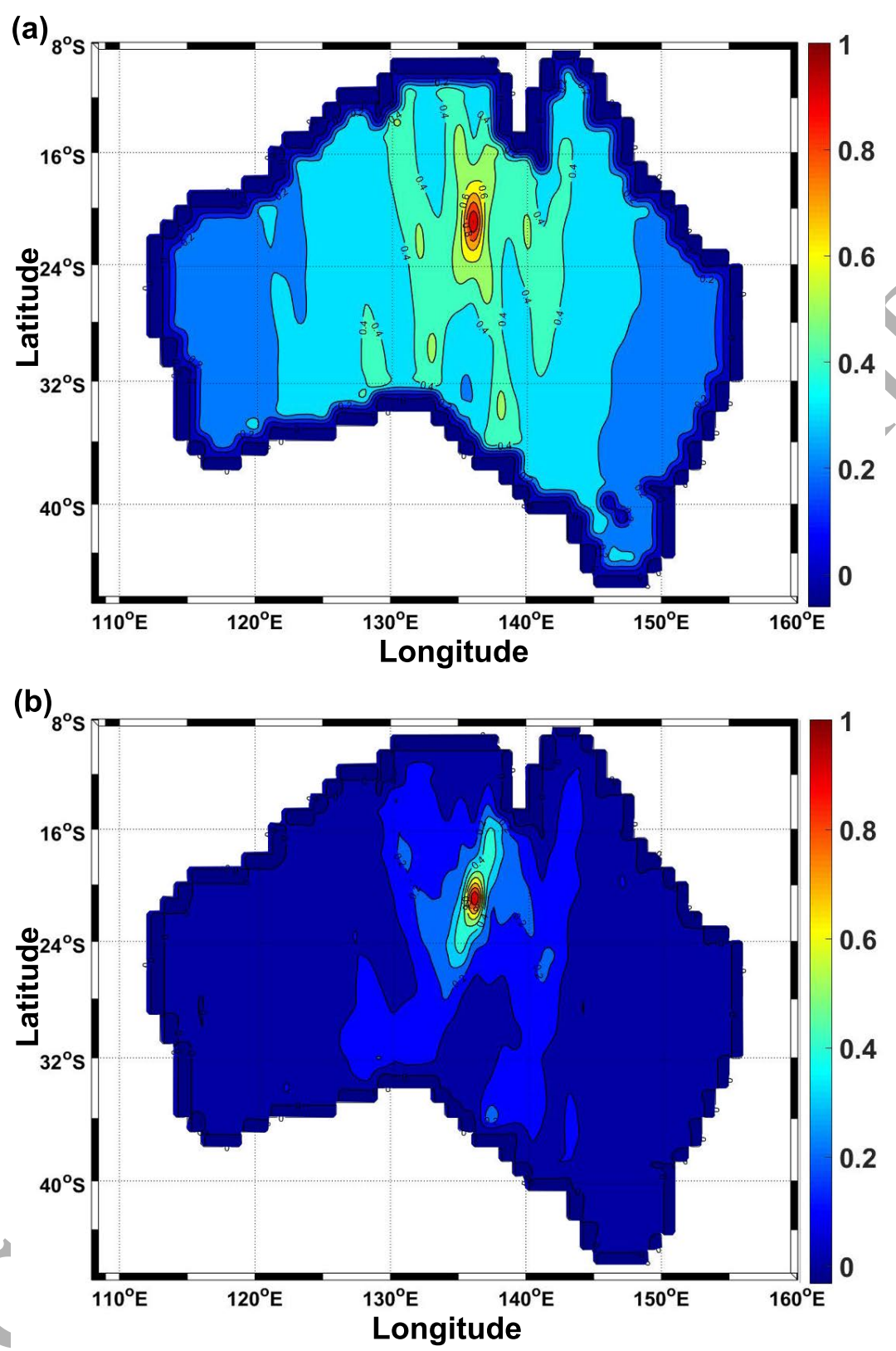

Figure 6: 2-D representation of correlation coefficients between the TWS anomalies of the arbitrary point $\left(136.6854^{\circ} \mathrm{E}\right.$ and $\left.23.9015^{\circ} \mathrm{S}\right)$ and the rest of the grid points. The temporal average of the correlation coefficients before and after assimilation using LA are shown in (a) and (b) respectively. 


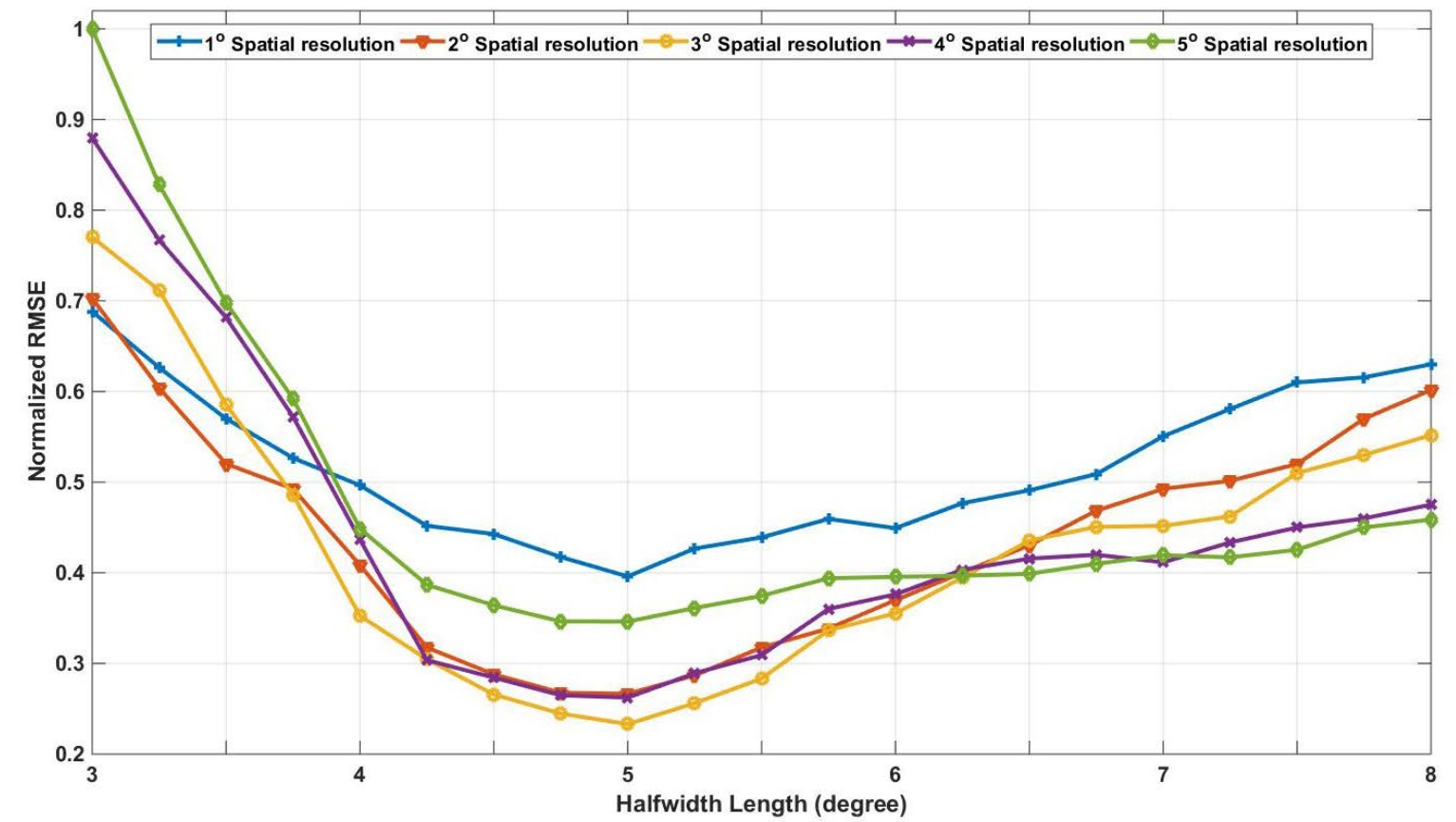

Figure 7: Comparison between normalized RMSE of TWS anomalies for different localisation radii (degree) applied for each case of GRACE TWS spatial resolution used for assimilation. RMSEs are calculated in mm, however, for a better visual presentation, normalized values are presented.

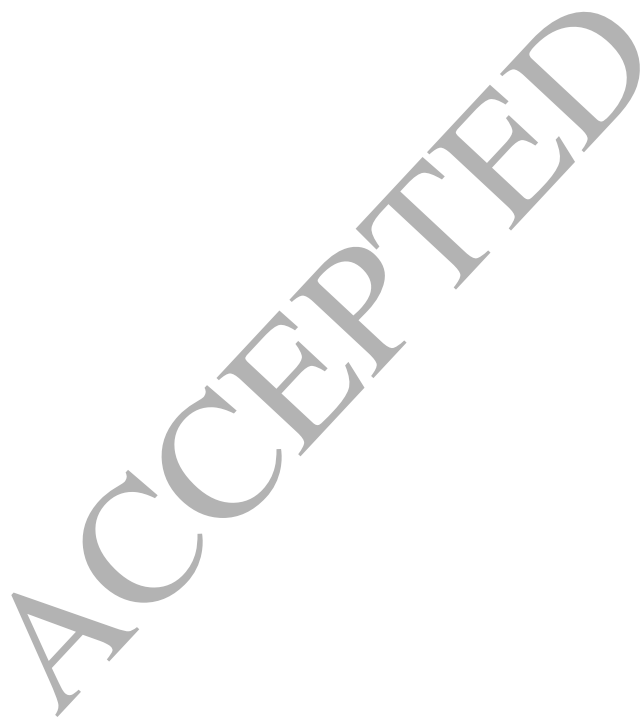




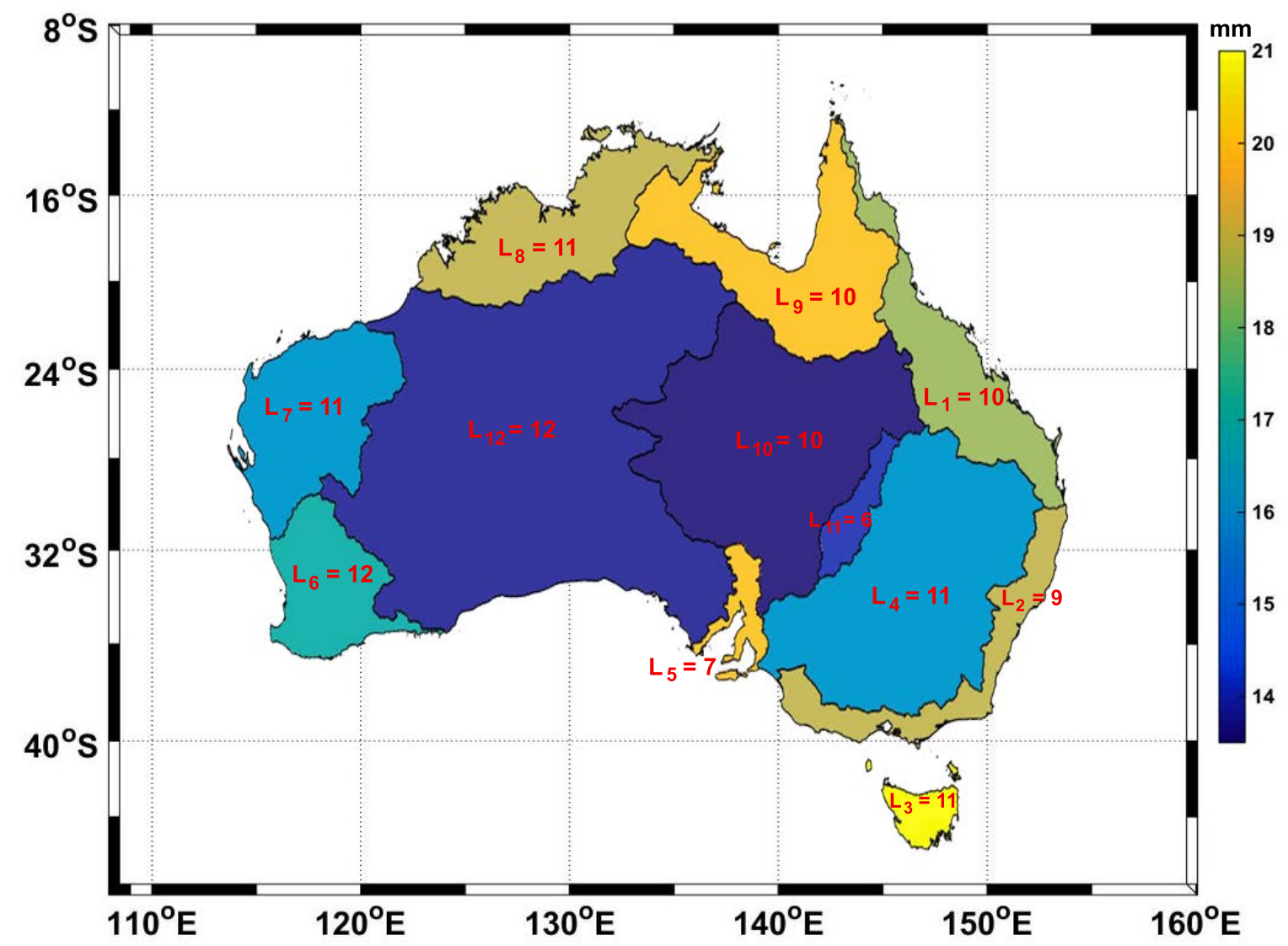

Figure 8: The estimated optimized/ocalisation radii (in degree and presented by L) and corresponding TWS errors with respect to the GRACE data for each basin. 
(a)

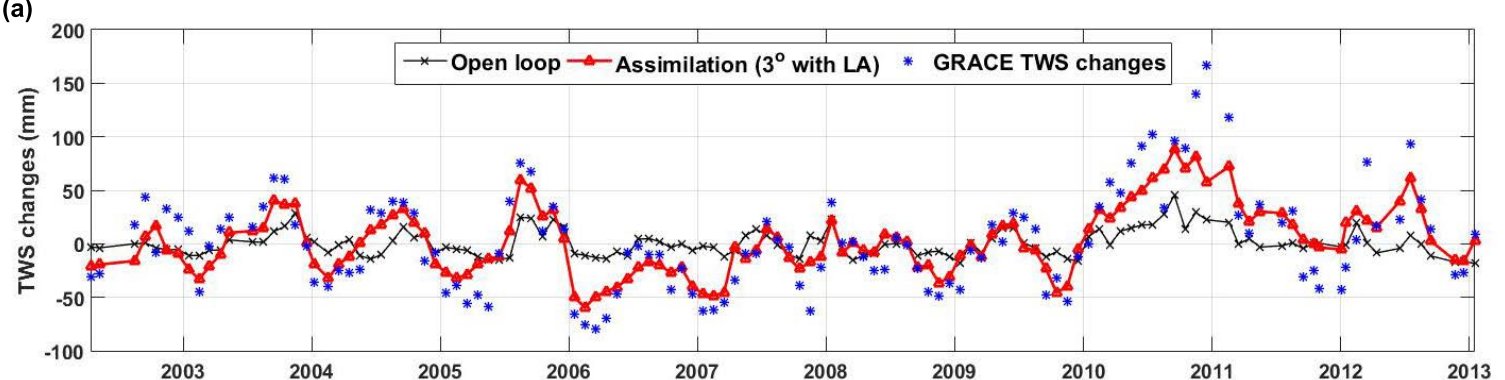

(b)

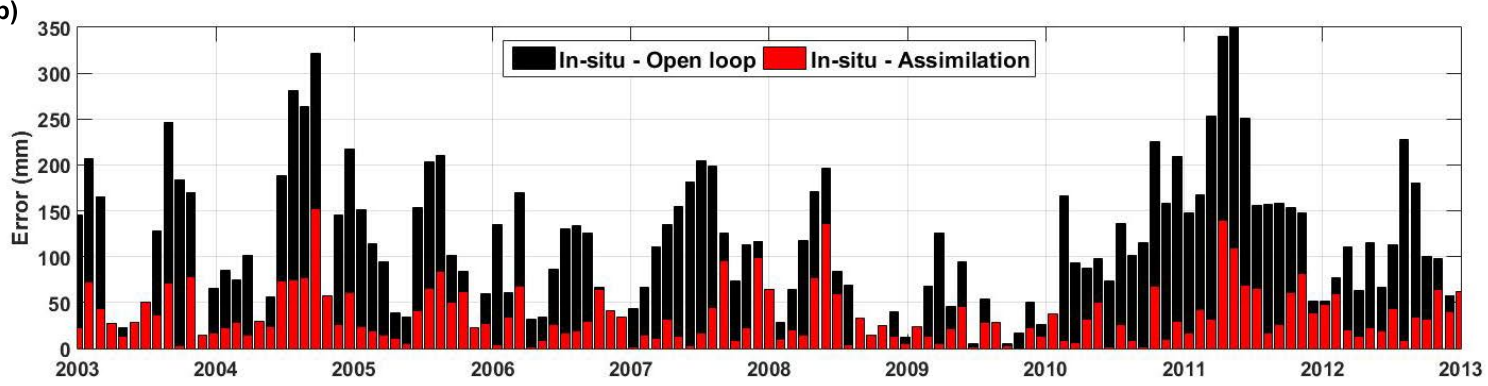

Figure 9: (a) Comparison between the TWS time series of the assimilation process for the case of $3^{\circ}$ spatial resolution (red), the GRACE observation (blue), with the open loop referring to the model estimation without applying data assimilation (black). (b) Absolute groundwater (GW) error bars before (black) and after (red) data assimilation process in comparison to the GW in-situ measurements. The time series shown in (a) and (b) are spatially averaged over the Murray-Darling Basin. 


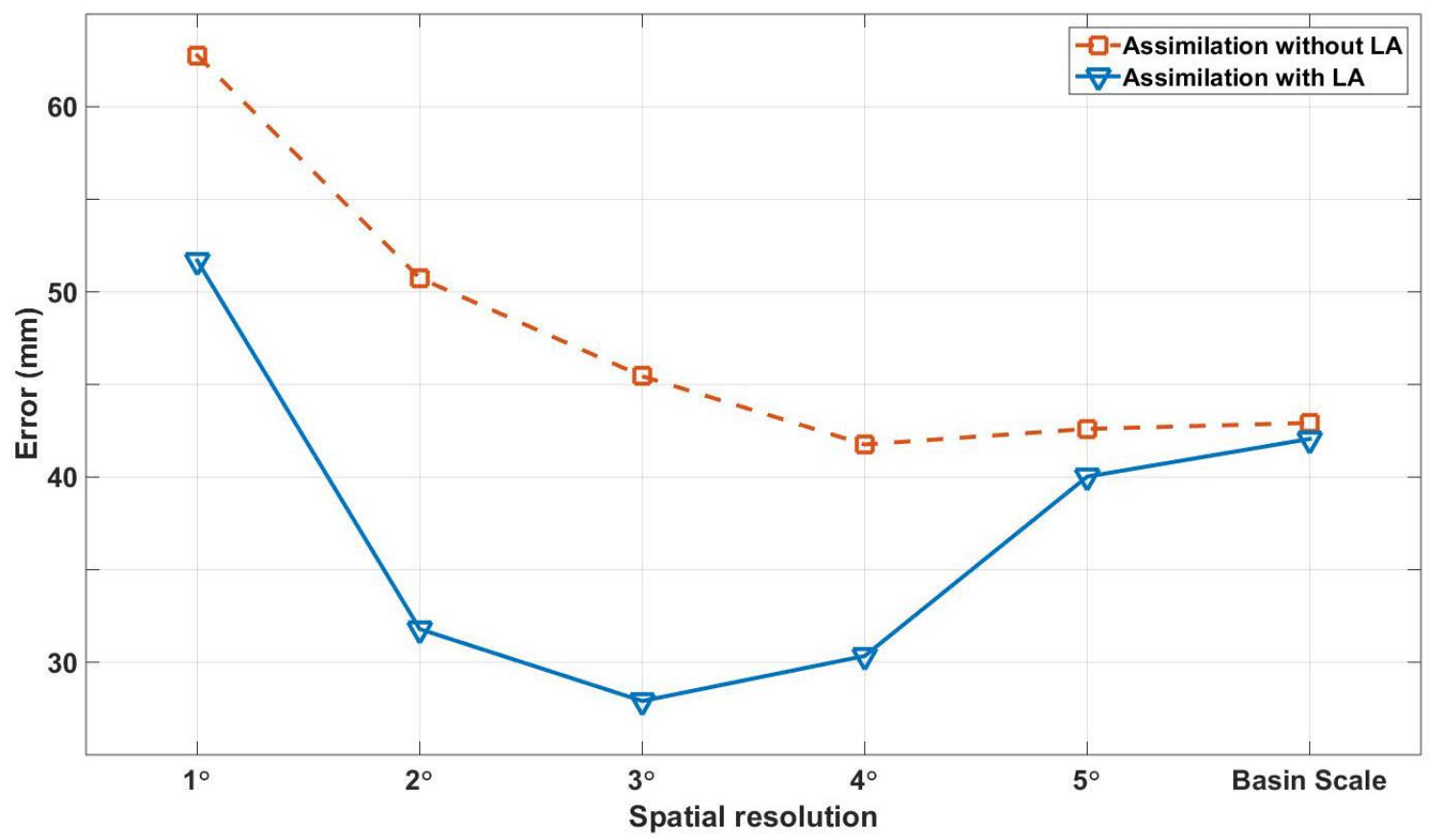

Figure 10: Average estimated error in groundwater anomalies from assimilating GRACE data for different spatial scales with (blue) and without (red) implementation of LA. The results are spatial averages over all groundwater data points within the Murray-Darling Basin. 


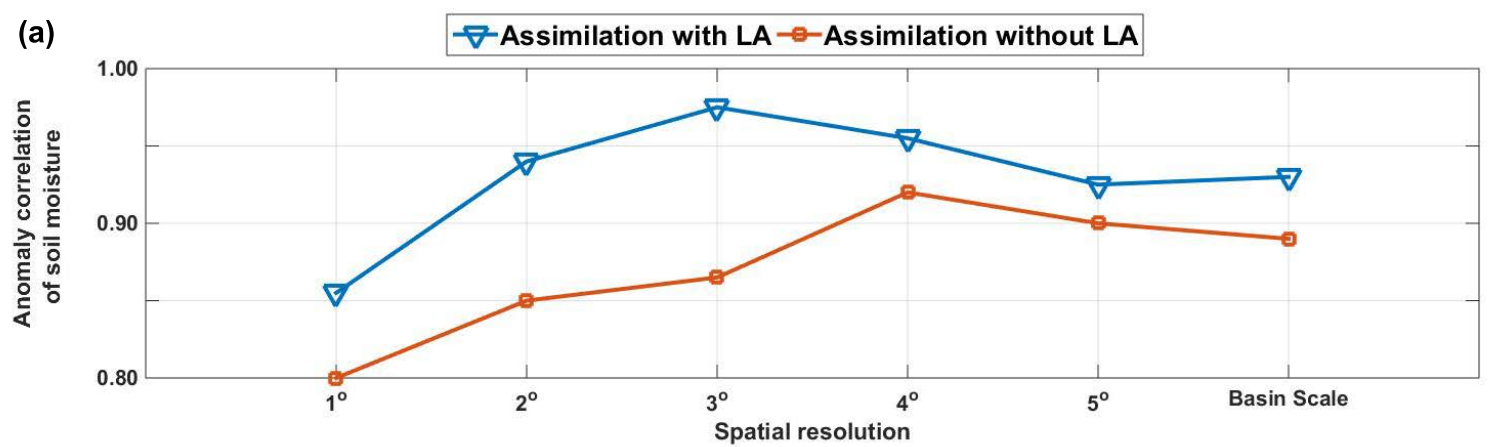

(b)

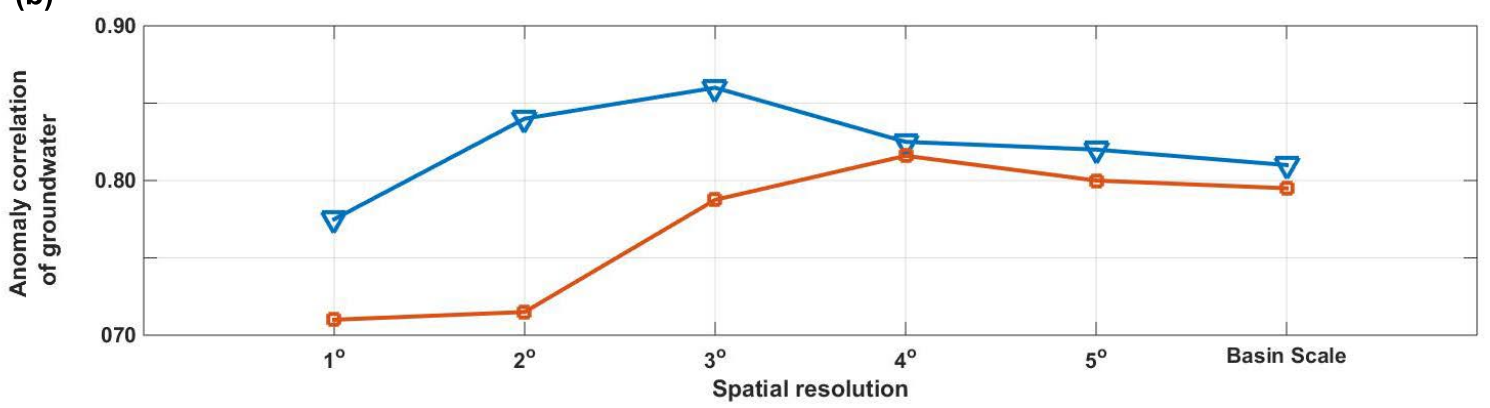

Figure 11: Comparison between the correlation of assimilation results (using different spatial resolutions) with OzNet soil moisture anomalies spatially averaged over the Murrumbidgee Catchment (a) and with anomalies of groundwater in-situ level measurements spatially averaged over the Murray-Darling Basin (b). The correlation results in both cases of data assimilation using LA (blue) and without using LA (red) are shown. 
Table 1: The details of GRACE observations used in each grid resolution.

\begin{tabular}{cccc}
\hline Spatial Scale & Observation Number & Rank & LA Rank \\
\hline $1^{\circ}$ & 794 & 268 & 794 \\
$2^{\circ}$ & 220 \\
$3^{\circ}$ & 111 & 211 & 220 \\
$4^{\circ}$ & 67 & 111 & 111 \\
$5^{\circ}$ & 45 & 67 & 67 \\
BasinScale & 12 & 45 & 45 \\
\hline
\end{tabular}

* Computed rank after the implementation of LA. 
Table 2: A summary of the results belonging to each scenario of data assimilation. Improvements in groundwater are calculated using the estimated RMSE with and without applying data assimilation (open loop) in relation to groundwater in-situ measurements.

\begin{tabular}{|c|c|c|c|c|}
\hline \multirow[b]{2}{*}{ Spatial Scale } & \multicolumn{2}{|c|}{ Assimilation without LA } & \multicolumn{2}{|c|}{ Assimilation with LA } \\
\hline & RMSE (mm) & Improvement (\%) & RMSE (mm) & Improvement (\%) \\
\hline $1^{\circ}$ & 68.54 & 17 & 52.23 & 37.33 \\
\hline $2^{\circ}$ & 51.09 & 38.70 & 35.11 & 57.87 \\
\hline $3^{\circ}$ & 47.41 & 43.11 & 26.80 & 67.84 \\
\hline $4^{\circ}$ & 43.18 & 48.19 & 32.35 & 61.18 \\
\hline $5^{\circ}$ & & 46.76 & 41.19 & 50.58 \\
\hline BasinScale & & 47.40 & 41.93 & 49.69 \\
\hline
\end{tabular}

